Article

\title{
New Insights into Leaf Physiological Responses to Ozone for Use in Crop Modelling
}

\author{
Stephanie Osborne ${ }^{1,2, *}$, Divya Pandey ${ }^{2}$, Gina Mills ${ }^{1}$, Felicity Hayes ${ }^{1}\left(0\right.$, Harry Harmens ${ }^{1}(\mathbb{D}$, \\ David Gillies $^{2}$, Patrick Büker ${ }^{2}$ (D) and Lisa Emberson ${ }^{2}$ (D) \\ 1 Centre for Ecology and Hydrology, Environment Centre Wales, Bangor LL57 2UW, UK; \\ gmi@ceh.ac.uk (G.M.); fhay@ceh.ac.uk (F.H.); hh@ceh.ac.uk (H.H.) \\ 2 Stockholm Environment Institute, Environment Department, University of York, York YO10 5NG, UK; \\ pandey.divyaa85@gmail.com (D.P.); david.gillies@york.ac.uk (D.G.); patrick.bueker@giz.de (P.B.); \\ l.emberson@york.ac.uk (L.E.) \\ * Correspondence: steph_osborne@hotmail.co.uk; Tel.: +44-7906-877798
}

Received: 28 February 2019; Accepted: 23 March 2019; Published: 1 April 2019

\begin{abstract}
Estimating food production under future air pollution and climate conditions in scenario analysis depends on accurately modelling ozone $\left(\mathrm{O}_{3}\right)$ effects on yield. This study tests several assumptions that form part of published approaches for modelling $\mathrm{O}_{3}$ effects on photosynthesis and leaf duration against experimental data. In 2015 and 2016, two wheat cultivars were exposed in eight hemispherical glasshouses to $\mathrm{O}_{3}$ ranging from 22 to $57 \mathrm{ppb}$ ( $24 \mathrm{~h}$ mean), with profiles ranging from raised background to high peak treatments. The stomatal $\mathrm{O}_{3}$ flux (Phytotoxic Ozone Dose, POD) to leaves was simulated using a multiplicative stomatal conductance model. Leaf senescence occurred earlier as average POD increased according to a linear relationship, and the two cultivars showed very different senescence responses. Negative effects of $\mathrm{O}_{3}$ on photosynthesis were only observed alongside $\mathrm{O}_{3}$-induced leaf senescence, suggesting that $\mathrm{O}_{3}$ does not impair photosynthesis in un-senesced flag leaves at the realistic $\mathrm{O}_{3}$ concentrations applied here. Accelerated senescence is therefore likely to be the dominant $\mathrm{O}_{3}$ effect influencing yield in most agricultural environments. POD was better than $24 \mathrm{~h}$ mean concentration and AOT40 (accumulated $\mathrm{O}_{3}$ exceeding $40 \mathrm{ppb}$, daylight hours) at predicting physiological response to $\mathrm{O}_{3}$, and flux also accounted for the difference in exposure resulting from peak and high background treatments.
\end{abstract}

Keywords: ozone; air pollution; wheat; photosynthesis; leaf senescence; crop modelling

\section{Introduction}

The air pollutant ozone $\left(\mathrm{O}_{3}\right)$ reduces yield in many crops including wheat, rice, and soybean $[1,2]$. Ozone at the ground level forms from precursor gases-chiefly $\mathrm{NO}_{\mathrm{x}}$ and volatile organic compounds (VOCs) - in chemical reactions catalysed by sunlight and heat [3]. Concentrations over much of the Earth's land surface have approximately doubled since pre-industrial times, mainly due to anthropogenic emissions from vehicles, industry, and agriculture [4-6]. Annual mean surface $\mathrm{O}_{3}$ concentrations have largely stabilized in Europe since the year 2000 as a result of emission control policies [7,8], but continued increase to 2050 is likely across South and East Asia [9,10]. The pattern of $\mathrm{O}_{3}$ exposure across regions is also expected to change over coming decades. Short peak 'episodes' of very high concentrations are predicted to become more frequent in India and China [10,11], while in Europe and North America a decline in peak episode frequency, alongside steadily increasing annual mean $\mathrm{O}_{3}$ concentrations, was observed between 1990 and 2010 [12]. Modelling suggests this decline in peak episode frequency in Europe and North America is likely to continue to 2050 [10]. 
Model-based estimates of yield loss under future climate and air pollution scenarios represent a powerful way of highlighting yield benefits that could come from reduced surface $\mathrm{O}_{3}$ [13-16]. Global $\mathrm{O}_{3}$-induced wheat yield loss for the year 2000 has been estimated as ranging from $5 \%$ to $26 \%$, with potential additional losses of $1.5 \%$ to $10 \%$ predicted for $2030[13,14]$. However, nearly all large-scale assessments of $\mathrm{O}_{3}$-induced yield loss for wheat published to date have followed an empirical approach, where $\mathrm{O}_{3}$ concentration is simulated using a chemical transport model (CTM), concentration is linked to yield loss using response functions, and response is scaled up using crop production maps and agricultural statistics. An alternative is to use a process-based approach that could potentially produce more robust estimates of future yield, through inclusion of interactive effects between $\mathrm{O}_{3}, \mathrm{CO}_{2}$, and climate variables [17].

This process-based crop modelling approach builds on the development of methods for modelling $\mathrm{O}_{3}$ flux into leaves that have been made over recent decades $[18,19]$. These methods provide an hourly estimate of $\mathrm{O}_{3}$ dose reaching sites of damage in the leaf, creating the potential for $\mathrm{O}_{3}$ effects to be integrated into crop simulation models in a dynamic way. Studies applying $\mathrm{O}_{3}$ flux modelling have generally either used a multiplicative stomatal conductance $\left(g_{\text {sto }}\right)$ algorithm-described in prior research [20-22]—or followed a semi-mechanistic approach where $g_{\text {sto }}$ is estimated empirically from photosynthetic rate, which in turn is modelled using the biochemical model of Farquhar et al. [23], also described in [24,25]. Since most crop models simulate growth responses at daily (and less frequently, hourly) timesteps and can respond to a changing environment [26], integration of $\mathrm{O}_{3}$ effects into crop models is feasible, if plant response to $\mathrm{O}_{3}$ can be represented in the model formulation. Attempts have been made to integrate $\mathrm{O}_{3}$ effects and crop modelling [25,27], but few estimates of $\mathrm{O}_{3}$-induced crop yield loss using a dynamic approach have been published to date [28,29]. Reasons for slow progress include the challenge of upscaling responses from the leaf to the canopy, the need for species and cultivar-specific model parameters, and the incomplete understanding of physiological mechanisms driving $\mathrm{O}_{3}$-induced yield reduction [17]. This paper goes some way to addressing these issues and identifying future research direction that would benefit from empirical investigation targeted towards developing the models that are currently in development.

It is well established that $\mathrm{O}_{3}$ exposure can reduce yield in wheat [30-32] and can cause foliar injury, impaired photosynthesis, altered carbon translocation, and accelerated senescence [33,34]. However, the processes linking $\mathrm{O}_{3}$ uptake to these responses are not fully understood and it is not clear which are most important in driving ultimate yield loss. Once $\mathrm{O}_{3}$ has been taken up through stomata, reactions in the plant apoplast lead to the formation of reactive oxygen species (ROS), which can then react with and damage membranes and proteins [35]. Most plants have in-built defence mechanisms and can up-regulate antioxidants to detoxify ROS, but this comes at a carbon cost, meaning $\mathrm{O}_{3}$ damage to productivity often occurs before visible symptoms appear [35,36]. An $\mathrm{O}_{3}$-induced reduction in photosynthetic rate has been widely reported $[32,37,38]$, but quantifying the extent to which this is a direct effect of $\mathrm{O}_{3}$ on the photosynthetic mechanism, or indirect via changes to leaf pigmentation or $\mathrm{g}_{\text {sto }}$, has been a challenge for experimentalists. Disentangling direct $\mathrm{O}_{3}$ impacts on photosynthesis from the accelerated senescence response is also difficult. Some studies have observed reduced activity of the carbon-fixing enzyme ribulose-1,5-biphosphate carboxylase/oxygenase (rubisco) in response to $\mathrm{O}_{3}$ [39-41], leading to the hypothesis that 'instantaneous' effects of $\mathrm{O}_{3}$ on photosynthesis act via effects on this enzyme. The physiological mechanism underpinning the often-observed accelerated senescence response to $\mathrm{O}_{3}$ [42-46] is also unknown, although it has been hypothesized that it relates to long-term respiratory costs associated with detoxification and repair [25].

Several approaches for modelling $\mathrm{O}_{3}$ effects on photosynthesis and senescence have been published. In an early paper, Reich et al. proposed that ozone effects on a number of plant groups could be expressed via a linear relationship between exposure and growth [47]. Subsequent published approaches have attempted to model the separate effects of $\mathrm{O}_{3}$ on productivity and senescence and have tried to account for differential sensitivity across species. A function for modelling 'instantaneous' suppression of photosynthesis was proposed by Martin et al. [27], who simulated a linear reduction 
in carboxylation capacity of rubisco (the parameter $\mathrm{V}_{\mathrm{cmax}}$ in the model of Farquhar et al. [23]), above a threshold hourly flux value representative of the species or cultivar-specific detoxification capacity. A similar approach of $\mathrm{O}_{3}$ acting on $\mathrm{V}_{\mathrm{cmax}}$ was also used by Deckmyn et al. in their $\mathrm{O}_{3}$ damage module for forest trees, alongside an overnight repair mechanism and a parameter representing the respiratory cost of detoxification [48]. Ewert and Porter [25] applied a version of the Martin et al. 'short-term' function alongside a 'long-term' algorithm for modelling $\mathrm{O}_{3}$-induced senescence and assumed that 'short-term' photosynthetic suppression by $\mathrm{O}_{3}$ occurs throughout the leaf lifespan. Their senescence function assumes a linear reduction in mature leaf lifespan as accumulated $\mathrm{O}_{3}$ flux increases, and senescence comprises the final third of the mature leaf lifespan, during which time $\mathrm{V}_{\mathrm{cmax}}$ is assumed to decline linearly. In this function, onset and completion of leaf senescence therefore move progressively earlier and closer together as accumulated $\mathrm{O}_{3}$ flux increases. An alternative approach for modelling $\mathrm{O}_{3}$-induced senescence is applied in the multiplicative $\mathrm{DO}_{3} \mathrm{SE}$ model (Deposition of ozone for stomatal exchange), a gsto model which estimates accumulated $\mathrm{O}_{3}$ flux - known as the Phytotoxic Ozone Dose (POD) - to vegetation [18]. In this model, leaf senescence is induced by a threshold POD, which triggers curvilinear decline in leaf $g_{\text {sto }}$ with a fixed shape but variable decline rate $[20,49,50]$. The POD 'trigger' can be parameterized according to the sensitivity of the cultivar or species.

The integration of $\mathrm{O}_{3}$ damage functions, such as those described above, into crop models could improve yield estimates under $\mathrm{O}_{3}$ stress. Model development must however be guided by experimental evidence that identifies damage mechanisms and their relative importance, informs parameterization, and indicates likely degree of error. Models must also be able to replicate the response to different patterns of $\mathrm{O}_{3}$ exposure. For example, acute peaks in concentration have been observed to induce greater yield loss than consistent, moderate levels with the same 24-h mean exposure [51], and modelling methods need to be able to capture these nuances.

This study combines data from two independent $\mathrm{O}_{3}$ exposure experiments on European wheat that took place at the same experimental facility in 2015 and 2016 and used consistent protocols for data collection. We model the accumulated $\mathrm{O}_{3}$ flux to wheat flag leaves across different $\mathrm{O}_{3}$ treatments, using the multiplicative $\mathrm{DO}_{3} \mathrm{SE}$ model, to derive the $\mathrm{POD}_{0} \mathrm{SPEC}$ metric of $\mathrm{O}_{3}$ flux exposure $\left(\mathrm{mmol} \mathrm{m}^{-2} \mathrm{PLA}\right.$ day $^{-1}$ ). Exposure to $\mathrm{O}_{3}$ flux is then considered alongside leaf chlorophyll, $\mathrm{g}_{\text {sto, }}$, and photosynthesis responses in order to test key assumptions underpinning published $\mathrm{O}_{3}$ effect model functions. Firstly, with regards to $\mathrm{O}_{3}$ effects on leaf senescence, we (i) examine whether inter-cultivar differences in response are captured by current senescence functions and (ii) whether leaf senescence begins at an accumulated $\mathrm{O}_{3}$ flux 'trigger' value. Secondly, we examine whether $\mathrm{O}_{3}$ reduces $\mathrm{V}_{\text {cmax }}$ before-and therefore independent of-onset of $\mathrm{O}_{3}$-induced leaf senescence. Thirdly, we investigate if flux is a better predictor of the physiological response to $\mathrm{O}_{3}$ than concentration-based metrics and whether flux can account for differences in the pattern of $\mathrm{O}_{3}$ exposure (i.e., peak vs. background).

Our results reveal several insights about physiological responses to $\mathrm{O}_{3}$ that can add to the evidence base for designing $\mathrm{O}_{3}$ effect model functions. The two cultivars of European wheat studied here showed substantially different sensitivity to $\mathrm{O}_{3}$ in terms of their senescence response, indicating the importance of cultivar-specific parameterization in senescence functions. The study also finds that $\mathrm{O}_{3}$ effects on the photosynthetic mechanism are not observed in young flag leaves and are only seen following the onset of leaf senescence, suggesting that $\mathrm{O}_{3}$-induced accelerated senescence is more important than direct effects on photosynthesis in determining final yield.

\section{Results}

\subsection{Ozone Treatments in 2015 and 2016}

This study combines data from two independent experiments, which took place at the Centre for Ecology and Hydrology (CEH) air pollution exposure facility in 2015 and 2016. Both experiments gathered data on the physiological response of wheat cultivars to $\mathrm{O}_{3}$ exposure using consistent experimental design and data collection techniques. The main differences in these experiments were in 
the ozone concentration profiles to which plants were exposed. In 2015, two wheat cultivars, 'Mulika' and 'Skyfall', were exposed to eight $\mathrm{O}_{3}$ treatments. The treatments varied in their profile, with some characterized by acute peaks in concentration and others by a consistent background level (described in full in Section 4.1). In 2016, cv. 'Skyfall' was exposed to five $\mathrm{O}_{3}$ treatments, all with a 'peak' style profile. The treatments are named in this paper according to their severity and profile, these are 'low background' (LB), 'low peak' (LP), 'medium background' (MB), 'medium peak' (MP), 'high background' (HB), 'high peak' (HP), 'very high background, (VHB), and 'very high peak' (VHP).

Table 1 summarizes the $\mathrm{O}_{3}$ treatments using several exposure indices including the 24-h mean (ppb) and seasonal AOT40 (ppm h). It also quantifies exposure using $\mathrm{O}_{3}$ flux, or phytotoxic ozone dose (POD), which was modelled in this study using the multiplicative $\mathrm{DO}_{3} \mathrm{SE}$ model (described in more detail in the Methodology and Appendix A). Several different flux metrics are included in the table. Because most plants have the ability to detoxify a small quantity of $\mathrm{O}_{3}$, methods for quantifying $\mathrm{O}_{3}$ dose often use a threshold for flux accumulation with the threshold value representing the detoxification capacity. Previous experimental work in wheat has found that a threshold of six produces the closest fit between exposure and yield [50]. We therefore applied a threshold of six when calculating accumulated flux, to produce the POD 6 SPEC metric (where SPEC refers to the species-specific nature of the metric). However, as thresholds for physiological effects are not as well established, we have also calculated accumulated flux with no threshold, known hereafter as the $\mathrm{POD}_{0}$ SPEC. The mean daily POD $\mathrm{PPEC}_{\text {was }}$ also calculated, to represent the average level of exposure on a given day in each treatment.

Table 1. Summary of ozone $\left(\mathrm{O}_{3}\right)$ treatments administered in the 2015 and 2016 experiments. 24-h mean, AOT40, and mean daily peak $\mathrm{O}_{3}$ have been calculated over the full $\mathrm{O}_{3}$ exposure period, whereas the mean $\mathrm{POD}_{0} \mathrm{SPEC}, \mathrm{POD}_{0} \mathrm{SPEC}$, and $\mathrm{POD}_{6} \mathrm{SPEC}$ quantifies exposure in the flag leaf only (i.e., calculated over the period following flag leaf emergence).

\begin{tabular}{|c|c|c|c|c|c|c|c|}
\hline Season & $\begin{array}{c}\text { Ozone } \\
\text { Treatment }\end{array}$ & $\begin{array}{l}\text { 24-h Mean } \\
\quad(\mathrm{ppb})\end{array}$ & $\begin{array}{c}\text { AOT40 } \\
(\mathrm{ppm} \mathrm{h)}\end{array}$ & $\begin{array}{c}\text { Mean Daily } \\
\text { Peak } \mathrm{O}_{3} \\
(\mathrm{ppb})^{* *}\end{array}$ & $\begin{array}{l}\text { Mean Daily } \\
\text { POD }_{0} \text { SPEC } \\
\left(\mathrm{mmol} \mathrm{m}^{-2}\right. \\
\left.\text { PLA day }^{-1}\right)\end{array}$ & $\begin{array}{l}\text { POD }_{0} \text { SPEC } \\
(\mathrm{mmol} \\
\left.\mathrm{m}^{-2} \text { PLA }\right)\end{array}$ & $\begin{array}{c}\text { POD }_{6} \text { SPEC } \\
(\text { mmol } \\
\left.\mathrm{m}^{-2} \text { PLA }\right)\end{array}$ \\
\hline \multirow{8}{*}{2015} & LB & 26.94 & 0.002 & 33.21 & 0.43 & 22.87 & 6.64 \\
\hline & LP & 30.39 & 0.02 & 36.44 & 0.46 & 25.19 & 8.17 \\
\hline & MB & 37.42 & 4.19 & 47.74 & 0.57 & 29.91 & 13.03 \\
\hline & MP & 40.39 & 14.51 & 67.59 & 0.69 & 30.99 & 15.95 \\
\hline & $\mathrm{HB}$ & 50.06 & 12.49 & 56.73 & 0.71 & 31.10 & 15.8 \\
\hline & $\mathrm{HP}$ & 50.14 & 28.56 & 91.90 & 0.82 & 31.79 & 18.48 \\
\hline & VHB & 56.81 & 19.45 & 66.28 & 0.78 & 31.42 & 17.36 \\
\hline & VHP & 55.73 & 40.03 & 116.55 & 1.07 & 32.16 & 20.55 \\
\hline \multirow{5}{*}{2016} & LP1 & 23.42 & 0.01 & 31.44 & 0.36 & 17.66 & 3.47 \\
\hline & LP2 & 22.05 & 0.03 & 30.73 & 0.34 & 17.11 & 2.93 \\
\hline & MP & 30.41 & 6.003 & 55.75 & 0.54 & 27.36 & 11.90 \\
\hline & $\mathrm{HP}$ & 39.72 & 21.25 & 81.04 & 0.78 & 31.87 & 17.39 \\
\hline & VHP & 50.14 & 37.54 & 113.93 & 1.04 & 33.91 & 20.72 \\
\hline
\end{tabular}

\subsection{Effect of $\mathrm{O}_{3}$ on Senescence}

Leaf senescence in the two cultivars across different $\mathrm{O}_{3}$ treatments was compared using chlorophyll content index (CCI) as a proxy measure for senescence. The growing seasons were divided into six segments or 'bins' of equal thermal time, and statistical analysis testing for the impact of $\mathrm{O}_{3}$ was carried out within each time-bin, in order to identify the point in the season when $\mathrm{O}_{3}$ effects on CCI can be seen to occur. CCI declined over the course of the growing seasons in both cultivars and in both years, and $\mathrm{O}_{3}$ accelerated this senescence (Figure 1). A substantial difference in senescence response of the two cultivars was observed. In the 2015 experiment, cv. Mulika exhibited $\mathrm{O}_{3}$-induced early senescence only in the highest treatment (VHP) (Figure 1A), whereas for cv. Skyfall in the same year, all treatments exhibited accelerated senescence relative to the lowest treatment (Figure 1B). 
In 2016, for Skyfall the three highest $\mathrm{O}_{3}$ treatments exhibited accelerated senescence (Figure 1C). A statistical summary of this analysis is reported in Table A3 of the Appendix A.
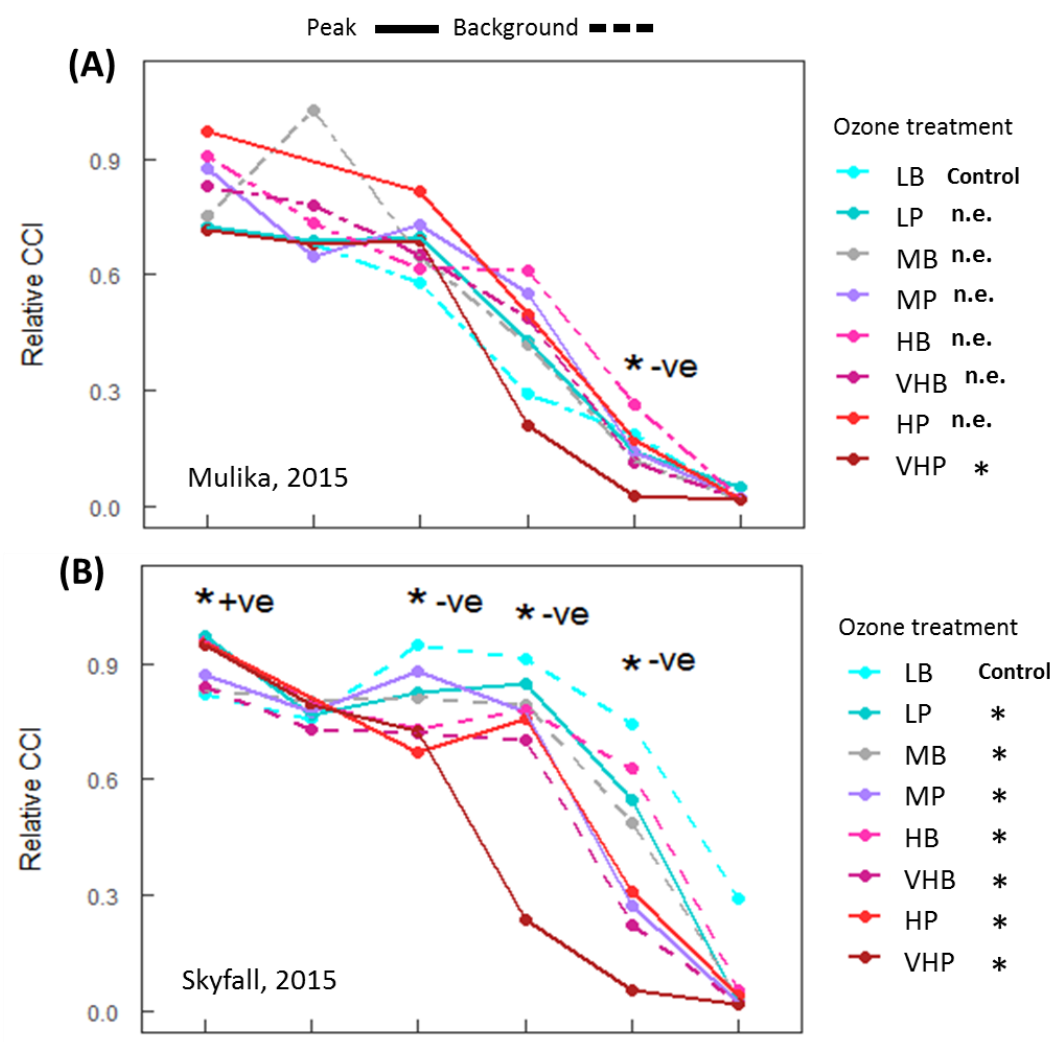

Ozone treatment

$\rightarrow$ LB Control

$\rightarrow$ LP *

$\multimap \mathrm{MB} *$

$\approx \mathrm{MP} *$

$\leadsto$ HB *

$\leadsto \mathrm{VHB} *$

$\multimap \mathrm{HP} \quad *$

$\sim$ VHP *

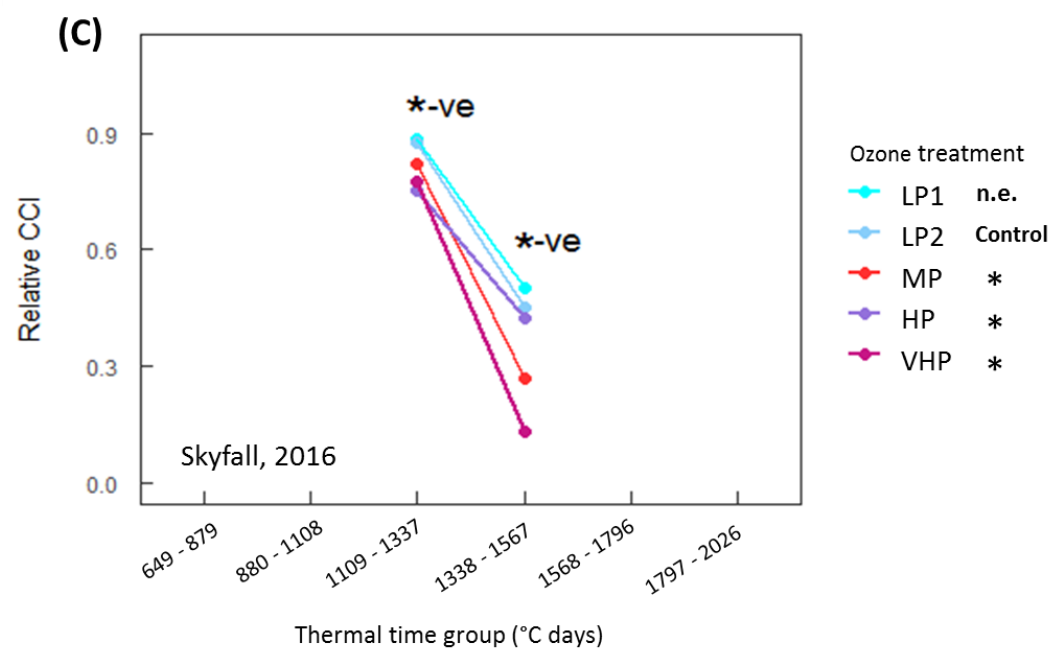

Figure 1. Average relative chlorophyll content index (CCI) in flag leaves for six thermal time groups, (A) cv. Mulika in 2015, (B) cv. Skyfall in 2015 and (C) cv. Skyfall in 2016. Time-bins where a statistically significant association between $\mathrm{CCI}$ and accumulated $\mathrm{POD}_{0}$ SPEC was observed are marked with an asterisk (*). The direction of $\mathrm{O}_{3}$ effect, i.e., positive (+ve) or negative ( - ve) effect on CCI, is also shown. Ozone treatments which exhibited a significant early decline (defined as a decline in CCI of $10 \%$ or more relative to the control treatments) are marked in the figure keys with asterisks $\left(^{*}\right)$, and those which showed no effect are marked as n.e. (no effect).

Analysis conducted within different thermal time groupings indicated that a significant negative effect of $\mathrm{O}_{3}$ on $\mathrm{CCI}$ was observed substantially earlier in the season for Skyfall compared to Mulika. For Skyfall in 2015, accumulated $\mathrm{POD}_{0}$ SPEC was significantly negatively associated with flag leaf CCI from the third thermal time group onwards $\left(1109-1337^{\circ} \mathrm{C}\right.$ days), after $25-36$ days of $\mathrm{O}_{3}$ exposure. 
For Mulika in 2015, accumulated $\mathrm{POD}_{0}$ SPEC was significantly negatively associated with CCI only at the fifth thermal time group $\left(1568-1796{ }^{\circ} \mathrm{C}\right.$ days), after $49-59$ days of $\mathrm{O}_{3}$ exposure. The limited CCI data for Skyfall in 2016 supports the 2015 results, with a significant negative association between accumulated $\mathrm{POD}_{0}$ SPEC and CCI observed in the 3rd and 4th thermal time-bins. A significant positive association between accumulated $\mathrm{POD}_{0}$ SPEC and CCI was observed for Skyfall in 2015, in thermal time group one $\left(649-879{ }^{\circ} \mathrm{C}\right.$ days) spanning the first 14 days of $\mathrm{O}_{3}$ exposure. A statistical summary of the time-bin analysis is presented in Table A4 of the Appendix A.

The timing of leaf senescence onset and completion was influenced by $\mathrm{O}_{3}$ exposure. For both cultivars in 2015, leaf senescence onset occurred earlier in $\mathrm{O}_{3}$ treatments with higher mean daily $\mathrm{POD}_{0} \mathrm{SPEC}$, although this trend was only statistically significant for Mulika (Figure 2A). On average, $\mathrm{O}_{3}$-induced senescence onset occurred later in the season for Mulika $\left(1725^{\circ} \mathrm{C}\right.$ days) compared to Skyfall ( $1216{ }^{\circ} \mathrm{C}$ days). Senescence completion also occurred earlier in $\mathrm{O}_{3}$ treatments with a higher mean daily $\mathrm{POD}_{0} \mathrm{SPEC}$ in both cultivars, according to a linear relationship (Figure 2B). Senescence completion occurred at a similar thermal time on average for both cultivars (Mulika $=1841^{\circ} \mathrm{C}$ days, Skyfall $=1867^{\circ} \mathrm{C}$ days). The total duration of the $\mathrm{O}_{3}$-induced senescence period was therefore longer for Skyfall than Mulika.

Skyfall also exhibited a linear reduction in the CCI-thermal time curve integral as the mean daily $\mathrm{POD}_{0}$ SPEC increased (Figure 2C). This indicates that Skyfall exhibited reduced CCI in the flag leaf throughout the post-anthesis period in elevated $\mathrm{O}_{3}$. No significant association between mean exposure and curve integral was found for Mulika, although the highest treatment in terms of mean flux exposure (VHP) did exhibit a reduced integral compared to the other treatments.

\subsection{Ozone Flux at Onset of Early Senescence}

Leaf senescence data was also analysed to test whether a particular quantity of $\mathrm{O}_{3}$ flux, or 'trigger' flux value, could be identified as inducing the onset of leaf senescence. Accumulated $\mathrm{O}_{3}$ flux at leaf senescence onset for all 2015 treatments which exhibited significant accelerated senescence is shown in Table 2. In the highest $\mathrm{O}_{3}$ treatment (VHP), senescence onset occurred at a substantially lower accumulated $\mathrm{POD}_{0}$ SPEC for the cultivar Skyfall $\left(25.7 \mathrm{mmol} \mathrm{m}^{-2}\right)$ compared with Mulika $\left(30.1 \mathrm{mmol} \mathrm{m}^{-2}\right)$, indicating differential sensitivity across the cultivars. When accumulated $\mathrm{POD}_{0} \mathrm{SPEC}$ and $\mathrm{POD}_{6} \mathrm{SPEC}$ at senescence onset are compared across the different $\mathrm{O}_{3}$ treatments for the cultivar Skyfall, senescence onset was observed to occur across a fairly wide range of accumulated flux (15.3-25.7 $\mathrm{mmol} \mathrm{m}^{-2} \mathrm{POD}_{0}$ SPEC, $6.5-18.6 \mathrm{mmol} \mathrm{m}^{-2} \mathrm{POD}_{6} \mathrm{SPEC}$ ). The range of flux at senescence onset was more narrow when flux was calculated without a detoxification threshold $\left(\mathrm{POD}_{0} \mathrm{SPEC}\right.$ flux range $=10.4 \mathrm{mmol} \mathrm{m}^{-2}, \mathrm{POD}_{6} \mathrm{SPEC}$ flux range $=12.1 \mathrm{mmol} \mathrm{m}^{-2}$ ) and considerably more narrow when only the five highest $\mathrm{O}_{3}$ treatments which exhibited the strongest accelerated senescence response are considered $\left(\mathrm{POD}_{0} \mathrm{SPEC}\right.$ flux range of five highest treatments $=3.7 \mathrm{mmol} \mathrm{m}^{-2}, \mathrm{POD}_{6} \mathrm{SPEC}$ flux range of five highest treatments $=5.7 \mathrm{mmol} \mathrm{m}^{-2}$ ).

Table 2. Accumulated flux (PODYSPEC) at the onset of $\mathrm{O}_{3}$-induced senescence for 2015 treatments which exhibited significant accelerated senescence.

\begin{tabular}{|c|c|c|c|}
\hline Cultivar & $\mathrm{O}_{3}$ Treatment & $\begin{array}{l}\text { POD }_{0} \text { SPEC at Senescence Onset } \\
\left(\mathrm{mmol} \mathrm{m}^{-2}\right)\end{array}$ & $\begin{array}{l}\text { POD }_{6} \text { SPEC at Senescence Onset } \\
\left(\mathrm{mmol} \mathrm{m}^{-2}\right)\end{array}$ \\
\hline \multirow[t]{7}{*}{ Skyfall } & LP & 17.8 & 6.5 \\
\hline & MB & 15.3 & 7.9 \\
\hline & MP & 22.0 & 12.9 \\
\hline & $\mathrm{HB}$ & 24.7 & 14.1 \\
\hline & $\mathrm{HP}$ & 25.1 & 16.2 \\
\hline & VHB & 22.9 & 14.4 \\
\hline & VHP & 25.7 & 18.6 \\
\hline Mulika & VHP & 30.1 & 20.6 \\
\hline
\end{tabular}



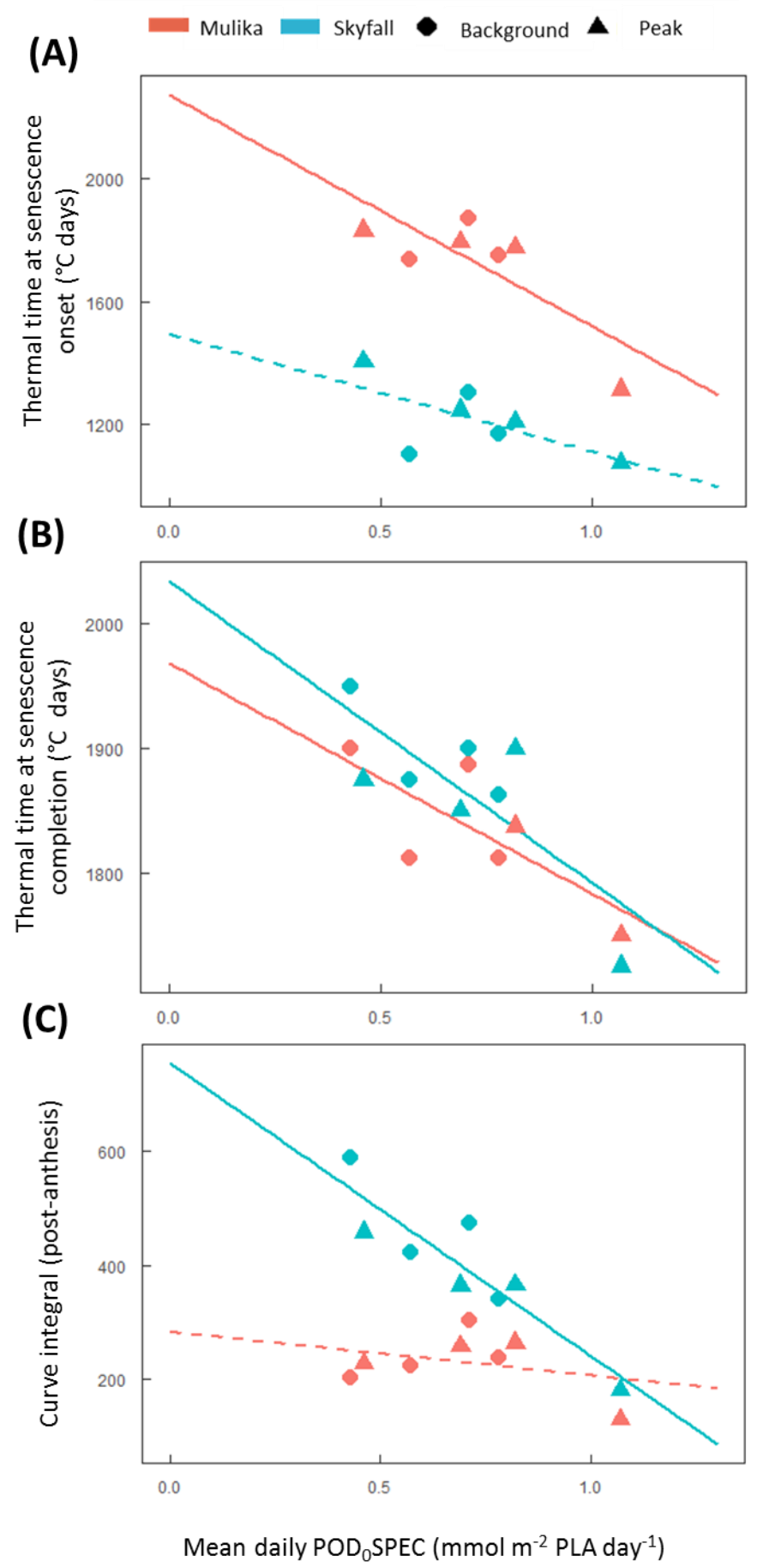

Figure 2. Effect of $\mathrm{O}_{3}$ on the onset and completion of leaf senescence in 2015. (A) Thermal time at senescence onset versus the mean daily $\mathrm{POD}_{0} \mathrm{SPEC}$ in each treatment. (B) Thermal time at senescence completion versus mean daily $\mathrm{POD}_{0} \mathrm{SPEC}$ in each treatment. (C) Area under the post-anthesis section of the CCI-thermal time curve versus the mean daily $\mathrm{POD}_{0} \mathrm{SPEC}$ in each treatment. Solid trend lines indicate a significant regression $(p<0.05)$, dashed lines indicate that the trend was not significant.

\subsection{Response of Photosynthesis and $g_{\text {sto }}$ Over Time and in Elevated $\mathrm{O}_{3}$}

Figure 3 presents combined datasets for four leaf-level physiological parameters capable of short-term or 'instantaneous' change in response to environmental stimuli: $A_{\text {sat }}$ (Light-saturated photosynthetic rate), $V_{c \max }$ (maximum carboxylation capacity of rubisco), $J_{\max }$ (maximum rate of electron transport) and $g_{\text {sto }}$ (stomatal conductance). Data from flag leaf measurements have been 
combined across both cultivars and both experiments, and the hue of each data point corresponds to the $\mathrm{POD}_{0} \mathrm{SPEC}$ that had accumulated at the time of measurement (an equivalent figure indicating accumulated $\mathrm{POD}_{6} \mathrm{SPEC}$ at time of measurement is shown as Figure A3 in the Appendix A). The average physiological values for high and low $\mathrm{O}_{3}$-treated plants within each time-bin are also shown on the plots. The average 'low' value represents the mean value for the lowest 2015 treatment (LB) and lowest 2016 treatment (LP2) combined. The average 'high' value represents the mean value for the highest 2015 treatment (VHP) and the highest 2016 treatment (VHP) combined. A decline in the photosynthetic parameters $\left(A_{\text {sat }}, V_{c \max }, J_{\max }\right)$ was observed across the growing season, and this decline was accelerated in high $\mathrm{O}_{3} . g_{\text {sto }}$ did not decline over time in low $\mathrm{O}_{3}$ but did decline throughout the season in high $\mathrm{O}_{3}$.

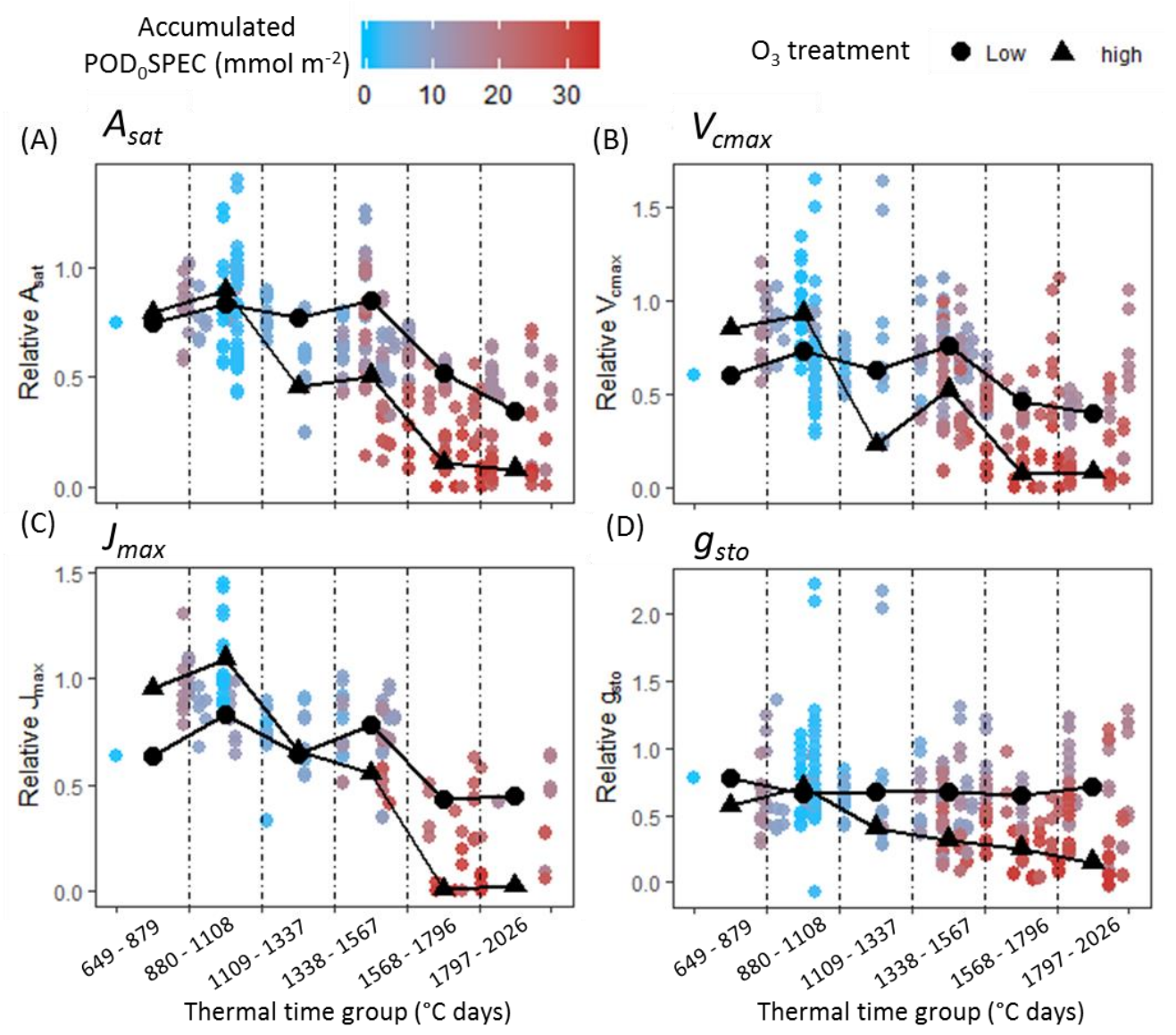

Figure 3. Flag leaf data for (A) $A_{s a t},(\mathbf{B}) V_{c \max },(\mathbf{C}) J_{\max }$, and (D) $g_{s t o}$, combined across all cultivar-year combinations. The hue of each data point corresponds to the accumulated $\mathrm{POD}_{0}$ SPEC at the moment of measurement. Mean values of physiological parameters in low $\mathrm{O}_{3}$-treated plants (averaged across 2015 LB and 2015 LP2 treatments) and high $\mathrm{O}_{3}$-treated plants (averaged across 2015 VHP and 2016 VHP treatments) are shown as black data points on the plots.

The outcome of statistical analyses carried out on each cultivar-year combination and in each thermal time group, for the parameters $A_{\text {sat }}, V_{\text {cmax }}, J_{\max }$, and $g_{\text {sto }}$ as measured in the flag leaves, is shown in Figure 4. A statistical summary of this analysis is presented in Tables A5-A8 of the Appendix A. Grey regions on plots denote the period following the observation of a significant negative effect of accumulated $\mathrm{POD}_{0} \mathrm{SPEC}$ on flag leaf CCI. Across all cultivar-year combinations, no significant negative effects of accumulated $\mathrm{POD}_{0}$ SPEC on any of the instantaneous physiological parameters was observed before negative effects of accumulated $\mathrm{POD}_{0}$ SPEC on CCI were observed. A significant negative association of accumulated $\mathrm{POD}_{0} \mathrm{SPEC}$ on the parameters $V_{c \max }$ and $J_{\max }$ was not observed until the 5th thermal time-bin (1568-1796 ${ }^{\circ} \mathrm{C}$ days). 

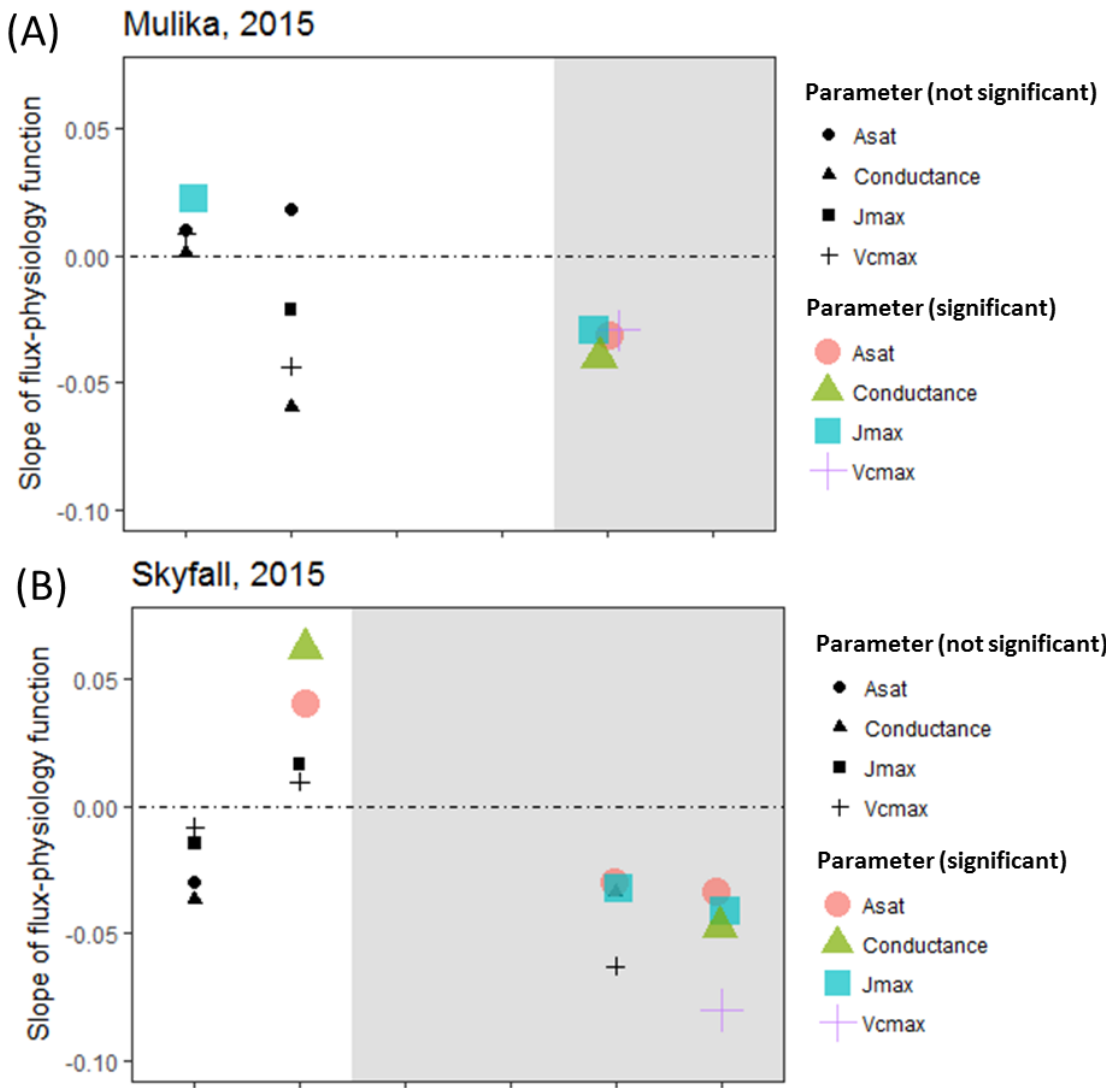

(C) Skyfall, 2016

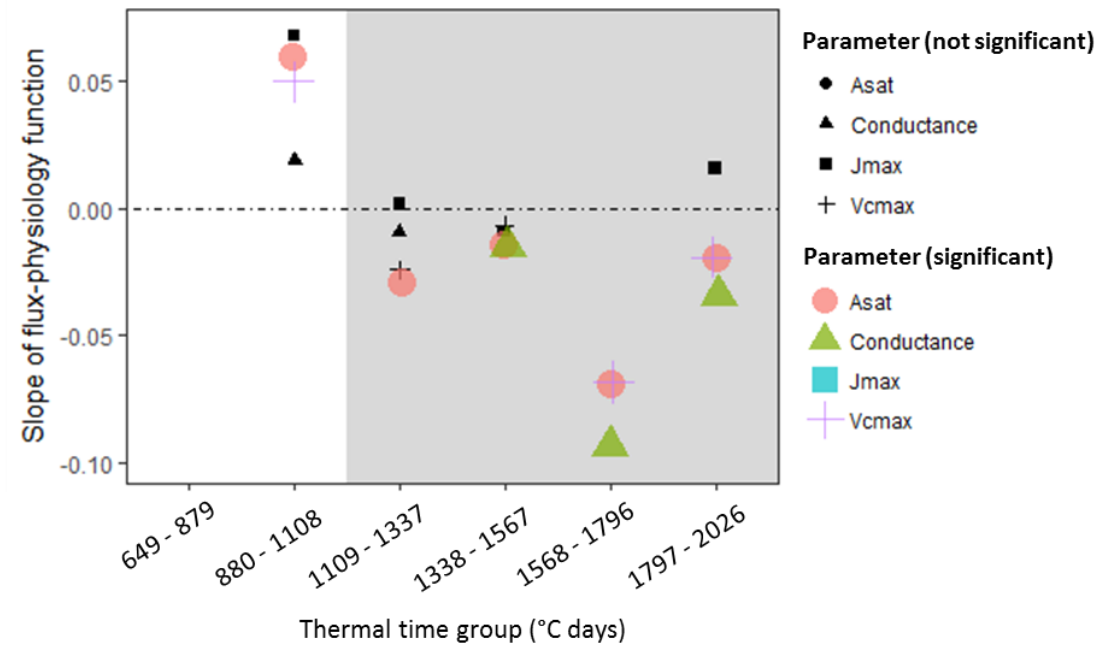

Figure 4. Plots showing the response of $A_{s a t}, V_{c \max }, J_{\max }$, and $g_{\text {sto }}$ to $\mathrm{O}_{3}$ flux. The y-axis represents the accumulated $\mathrm{POD}_{0}$ SPEC-physiology slope in the 'best' linear mixed regression model for each thermal time group. Positive slope indicates a positive effect of $\mathrm{O}_{3}$ on the physiological variable; a negative slope indicates a negative effect. (A) cv. Mulika in 2015, (B) cv. Skyfall in 2015, (C) cv. Skyfall in 2016. Coloured symbols indicate a significant $\mathrm{POD}_{0}$ SPEC-physiology association; black symbols indicate no statistically significant physiological response. Grey regions on plots indicate the period following an observed significant effect of $\mathrm{O}_{3}$ on flag leaf CCI.

Some evidence of heightened physiological performance in the early-season in high $\mathrm{O}_{3}$ was observed across both cultivars and both years, although the pattern was not consistent. A significant positive association between accumulated POD 0 SPEC and physiology in either the first or second 
time-bin was observed for i) $J_{\max }$ in Mulika in 2015, ii) $A_{\text {sat }}$ and $g_{s t o}$ in Skyfall in 2015, and iii) $A_{\text {sat }}$ and $V_{c m a x}$ in Skyfall in 2016.

\subsection{Comparison of $\mathrm{O}_{3}$ Exposure Metrics for Predicting Physiological Response to $\mathrm{O}_{3}$}

For all measured physiological parameters (CCI, $\left.A_{s a t}, V_{c \max }, J_{\max }, g_{\text {sto }}\right)$ and for both cultivars, a flux-based metric of exposure was better at predicting physiological response of wheat to $\mathrm{O}_{3}$, compared to the concentration-based metrics (24-h mean and AOT40) (Table 3). For four out of the ten model sets created in this analysis, the accumulated $\mathrm{POD}_{0}$ SPEC (i.e., without a threshold for accumulation) produced the best model fit. For the other six model sets, the accumulated $\mathrm{POD}_{0} \mathrm{SPEC}$ and $\mathrm{POD}_{6} \mathrm{SPEC}$ metrics were equally good at predicting physiological response. The $\mathrm{O}_{3}$ flux metric with no threshold for accumulation was therefore equal to, or better than, the $\mathrm{O}_{3}$ flux metric with a detoxification threshold at predicting the physiological response to $\mathrm{O}_{3}$.

Table 3. Summary of linear mixed model regression analysis to determine whether accumulated $\mathrm{POD}_{0} \mathrm{SPEC}$, accumulated $\mathrm{POD}_{6} \mathrm{SPEC}, 24-\mathrm{h}$ mean, or AOT40 represent the best predictor of physiology in the $5^{\text {th }}$ thermal time-bin. The lowest AIC (Akaike Information Criterion) for each parameter and cultivar, indicating the best model, is highlighted in grey. The outcome of model selection to determine if the profile of $\mathrm{O}_{3}$ exposure (i.e., peak vs. background) was important in the flux-based models is also shown.

\begin{tabular}{|c|c|c|c|c|c|c|c|}
\hline Parameter & Cultivar & $\begin{array}{c}\text { AIC: } \\
\text { POD }_{0} \text { SPEC }\end{array}$ & $\begin{array}{c}\text { AIC: } \\
\text { POD }_{6} \text { SPEC }\end{array}$ & $\begin{array}{c}\text { AIC: } \\
\text { AOT40 }\end{array}$ & $\begin{array}{l}\text { AIC: } 24-h \\
\text { Mean }\end{array}$ & $\begin{array}{c}\mathrm{O}_{3} \text { Profile } \\
\text { Important in } \\
\text { POD }{ }_{0} \text { SPEC } \\
\text { Model? }\end{array}$ & $\begin{array}{c}\mathrm{O}_{3} \text { Profile } \\
\text { Important in } \\
\text { POD } 6 \text { SPEC } \\
\text { Model? }\end{array}$ \\
\hline \multirow[t]{2}{*}{$\mathrm{CCI}$} & Mulika & -62.8 & -60.5 & -59.2 & -58.3 & No & No \\
\hline & Skyfall & 3.7 & 10.4 & 12.3 & 15.0 & No & No \\
\hline \multirow[t]{2}{*}{$A_{\text {sat }}$} & Mulika & -0.5 & 1.3 & 4.1 & 3.2 & No & No \\
\hline & Skyfall & -82.9 & -68.0 & -48.1 & -54.2 & No & No \\
\hline \multirow[t]{2}{*}{$V_{\text {cmax }}$} & Mulika & 6.1 & 6.9 & 9.9 & 9.0 & No & No \\
\hline & Skyfall & -63.0 & -62.9 & -34.6 & -32.3 & No & No \\
\hline \multirow[t]{2}{*}{$J_{\max }$} & Mulika & -1.7 & 0.2 & 3.2 & 2.3 & No & No \\
\hline & Skyfall & 6.3 & 7.3 & 9.2 & 9.5 & Yes & No \\
\hline \multirow[t]{2}{*}{$g_{\text {sto }}$} & Mulika & 13.4 & 14.8 & 17.3 & 16.5 & No & No \\
\hline & Skyfall & -19.1 & -7.3 & 2.7 & -1.6 & No & No \\
\hline
\end{tabular}

The inclusion of an explanatory variable describing the profile (i.e., peak or background) of $\mathrm{O}_{3}$ exposure in the 'best' model did not improve fit in nine out of the ten model sets created with the accumulated $\mathrm{POD}_{0} \mathrm{SPEC}$ metric, and in all models created with the accumulated $\mathrm{POD}_{6} \mathrm{SPEC}$ metric. Using $\mathrm{O}_{3}$ flux as the metric of exposure therefore accounts for differences in the $\mathrm{O}_{3}$ exposure resulting from peak-dominated treatments and those featuring a consistent background level, in the majority of cases.

\section{Discussion}

The first aim of the analysis presented here was to assess whether published approaches for modelling $\mathrm{O}_{3}$-induced senescence can account for inter-cultivar variation in response. Both cultivars exhibited accelerated senescence in response to $\mathrm{O}_{3}$, but the pattern of response differed according to cultivar. In 2015, significant accelerated senescence was observed in seven $\mathrm{O}_{3}$ treatments for Skyfall, but only in the highest treatment for Mulika, suggesting higher $\mathrm{O}_{3}$ tolerance in Mulika (Figure 1). This differential tolerance is also indicated by the earlier appearance of significant $\mathrm{O}_{3}$ effects on leaf CCI across all treatments for Skyfall compared to Mulika. Senescence completion occurred progressively earlier, hence total leaf duration became progressively shorter, in both cultivars as average $\mathrm{O}_{3}$ flux (mean daily $\mathrm{POD}_{0} \mathrm{SPEC}$ ) in the treatment increased (Figure 2B), according to a linear relationship. Completion of leaf senescence occurred at a similar thermal time in both cultivars (Mulika $=1841^{\circ} \mathrm{C}$ days, Skyfall $=1867^{\circ} \mathrm{C}$ days), meaning that the total senescence duration was longer for Skyfall. While 
$\mathrm{O}_{3}$-induced senescence in Mulika was characterised by a sudden drop in leaf $\mathrm{CCI}$ in the late-season, Skyfall exhibited a more gradual $\mathrm{O}_{3}$-induced decline in CCI.

The linear relationship between mean flux and total leaf duration observed in this study for both cultivars gives support to the senescence function of Ewert and Porter [25], which assumes a linear decline in mature leaf lifespan as $\mathrm{O}_{3}$ exposure increases. However, evidence presented here suggests that the duration of leaf senescence is likely to vary with $\mathrm{O}_{3}$ exposure. Additionally, the differential senescence duration in the two cultivars suggests that a key assumption of the Ewert and Porter function - that leaf senescence comprises the final third of the mature leaf lifespan-may not hold true for all cultivars. For example, in 2015 for Skyfall, leaf senescence in the highest $\mathrm{O}_{3}$ treatment comprised $76.7 \%$ of the total flag leaf lifespan (flag leaf emergence $=877^{\circ} \mathrm{C}$ days, leaf senescence onset $=1075^{\circ} \mathrm{C}$ days, senescence completion $=1725^{\circ} \mathrm{C}$ days) - substantially greater than one third. The inter-cultivar variation in senescence response observed in this study would therefore only be captured by a model function that allows for the proportion of leaf lifespan comprising leaf senescence to be parameterised according to cultivar and ozone exposure. Our results suggest that to effectively model variation in the pattern of $\mathrm{O}_{3}$-induced senescence, the timing of senescence onset, and the rate (or duration) of senescence, models need to be calibrated for particular species and cultivars.

However, the analysis in this paper highlights the uncertainty associated with the approach of Danielsson et al. [20] for modelling onset of $\mathrm{O}_{3}$-induced senescence using a threshold of accumulated flux. Following this approach, senescence onset may occur at different points in time at different levels of mean exposure but should occur at approximately the same value of accumulated flux. This method was designed in the absence of a known mechanism for induction of senescence by $\mathrm{O}_{3}$ but could be interpreted mechanistically if accumulated $\mathrm{O}_{3}$ flux is assumed to be proportional to increased respiratory effort accumulated over the season, which has been proposed as a potential trigger for $\mathrm{O}_{3}$-induced senescence [25]. For Skyfall, across the five highest $\mathrm{O}_{3}$ treatments in 2015, onset occurred across a POD 0 SPEC range of $22.0-25.7 \mathrm{mmol} \mathrm{m}^{-2}$. Given the limitations associated with the method used to identify senescence onset-arbitrarily defined as a $10 \%$ reduction in leaf CCI relative to the control—as well as the inherent variation that exists between seedlings, this flux range can be considered relatively narrow. However, when all treatments that exhibited a significant $\mathrm{O}_{3}$ effect on senescence are considered for Skyfall in 2015, the range of flux at senescence onset is considerably wider (17.8-25.7 $\left.\mathrm{mmol} \mathrm{m}^{-2} \mathrm{POD}_{0} \mathrm{SPEC}\right)$. These results provide an estimate of the degree of error potentially associated with applying this approach in models and suggest that the accumulation of respiratory effort does not fully explain the triggering of $\mathrm{O}_{3}$-induced senescence.

A second objective of this study was to test the hypothesis that $\mathrm{O}_{3}$ reduces photosynthetic rate in the short term by reducing carboxylation capacity of rubisco $\left(V_{c \max }\right)$. The assumption that $\mathrm{O}_{3}$ reduces $V_{\text {cmax }}$ is central to the 'instantaneous' $\mathrm{O}_{3}$ effect function of Martin et al. [27]. A version of this function is also applied by Ewert and Porter [25], where $\mathrm{O}_{3}$ reduces photosynthesis in a short-term and reversible way, in addition to and independent of the $\mathrm{O}_{3}$ senescence effect. The analysis presented here found that a significant negative effect of $\mathrm{O}_{3}$ on photosynthesis and $g_{\text {sto }}$ was only observed concurrent with $\mathrm{O}_{3}$-induced leaf senescence (Figure 4). This result was consistent across all cultivar-year combinations. For Skyfall in 2015 and 2016, significant negative effects of $\mathrm{O}_{3}$ on $A_{\text {sat }}$ were observed before a negative association between $\mathrm{O}_{3}$ and $V_{c m a x}$, suggesting that reduced carboxylation capacity is not responsible for the initial reduction in photosynthetic capacity observed in these experiments. There was therefore no evidence of an 'instantaneous' effect of $\mathrm{O}_{3}$ on the photosynthetic mechanism, in the period preceding leaf senescence.

These results contradict several studies which observed short-term reduction in photosynthetic rate in response to $\mathrm{O}_{3}$ [39-41]. One possible explanation for this contradiction is that instantaneous reduction of carboxylation capacity by $\mathrm{O}_{3}$ is only relevant at acute concentrations. The reduced carboxylation efficiency reported by Farage et al. [41] was observed following 4-16 h of exposure at unrealistically high $\mathrm{O}_{3}$ concentrations of $200-400 \mathrm{ppb}$, considerably higher hourly concentrations compared to those used in the experiments in this study, which more closely mimic ambient 
conditions (maximum hourly $\mathrm{O}_{3}$ exposure of $117 \mathrm{ppb}$ ). The results presented here therefore indicate that accelerated senescence is likely to be more important than direct effects on photosynthesis for determining crop yield loss in most agricultural landscapes, where $\mathrm{O}_{3}$ concentrations are typically moderate (ranging from $\sim 20$ to $\sim 45 \mathrm{ppb}$ ) with occasional peaks in concentration [5,52]. Understanding and simulating the early senescence response to $\mathrm{O}_{3}$ should therefore be the priority for $\mathrm{O}_{3}$ experimentalists and modellers.

Alternatively, our results could be explained by a differential response to $\mathrm{O}_{3}$ in younger and older leaves. Bernacchi et al. [53] and Morgan et al. [54] observed in field experiments with soybean that $\mathrm{O}_{3}$ effects on photosynthesis and $g_{\text {sto }}$ were not apparent in new fully expanded leaves and Reichenauer et al. [55] saw similar results in three wheat cultivars. Younger leaves may have a higher tolerance to $\mathrm{O}_{3}$, or alternatively the $\mathrm{O}_{3}$ effect on photosynthesis may be associated with a cumulative build-up of $\mathrm{O}_{3}$ damage in leaves or leaf age. Either way, the age-dependency of $\mathrm{O}_{3}$ effects is an important consideration in $\mathrm{O}_{3}$ effects modelling. The function described by Ewert and Porter [25] for modelling short-term effects of $\mathrm{O}_{3}$ on photosynthesis allows for leaf age to influence the rate of overnight recovery from $\mathrm{O}_{3}$ damage but not the threshold for damage. The role of leaf age in determining $\mathrm{O}_{3}$ flux thresholds would benefit from further investigation.

A surprising result from the data analysis is that $\mathrm{O}_{3}$ had a significant positive effect on some physiological parameters early in the season. CCI, $A_{\text {sat }}, V_{\text {cmax }}$, and $g_{\text {sto }}$ all exhibited a positive association with $\mathrm{O}_{3}$ exposure for one or more of the cultivar-year combinations, in either the first or second thermal time group (up to 32 days following beginning of exposure). Stimulation of growth at low doses of a toxin is known as hormesis, and this phenomenon has been observed previously in a number of plants in response to exposure to low concentrations of $\mathrm{O}_{3}$ [56]. Stimulation of photosynthesis and $g_{\text {sto }}$ in wheat during the first few weeks of $\mathrm{O}_{3}$ exposure was also observed by Mulholland et al. [57] in their open-top chamber experiment, although generally there are few reported cases of this phenomenon in crop species. Ozone-induced physiological stimulation could be an adaptive response associated with plant defence responses, for example, heightened $g_{\text {sto }}$ and photosynthesis may enable the upregulation of antioxidant synthesis. Observations that yield can be stimulated at low $\mathrm{O}_{3}$ exposure concentrations have also given rise to the theory that free radicals, at low concentrations, can act as growth promotors in plants [58]. An alternative hypothesis is that the observed early-season physiological boost in this study is related to disruption of stomatal control by $\mathrm{O}_{3}$, as has been observed in some grassland species [59,60], leading to heightened $g_{\text {sto }}$ and an associated boost in other physiological parameters. Our results suggest that a bi-phase hermetic dose-response curve, such as proposed by Agathokleous et al. [56], could be considered in ozone effect functions. More experimental data is needed in order to establish if the early-season physiological boost induced by $\mathrm{O}_{3}$ in this study is consistent across other plant species and environments.

The third aim of this study was to test whether $\mathrm{O}_{3}$ flux would be a better predictor of physiological response than concentration-based exposure (AOT40 and 24-h mean). Flux was superior at predicting the response to $\mathrm{O}_{3}$ of five physiological variables $\left(\mathrm{CCI}, A_{\text {sat }}, V_{\text {cmax }}, J_{\max }, g_{\text {sto }}\right)$ in regression models, for both cultivars (Table 3). Previous studies have reported that flux is better than AOT40 at predicting the spatial distribution of $\mathrm{O}_{3}$ injury [61] and is a better predictor of the response of wheat yield, poplar biomass, and assimilation rate in urban trees to $\mathrm{O}_{3}$ exposure [62-64]. However, few have compared the association between leaf-level physiology and different exposure metrics in crop species. Our results align with the general consensus in the $\mathrm{O}_{3}$ research community that $\mathrm{O}_{3}$ flux represents a more biologically relevant metric of $\mathrm{O}_{3}$ exposure than ambient concentration [61,65-67] and indicate that $\mathrm{O}_{3}$ flux should be the preferred metric of exposure in $\mathrm{O}_{3}$ effect model functions. More surprising is the fact that the flux metric without an accumulation threshold, $\mathrm{POD}_{0} \mathrm{SPEC}$, was a better or equal predictor of physiological response compared to $\mathrm{POD}_{6} \mathrm{SPEC}$, which employs an accumulation threshold of six. $\mathrm{POD}_{6}$ SPEC produced the closest correlation between flux and yield of wheat in a previous analysis testing different flux accumulation thresholds [50] and has been applied in several assessments of $\mathrm{O}_{3}$ impacts in wheat $[22,68]$. More research is therefore needed to establish how much the capacity 
to detoxify $\mathrm{O}_{3}$ varies between cultivars and why the threshold flux required to induce leaf-level physiological changes appears to differ from the threshold required to reduce yield. This result also highlights the limitations of an empirical rather than a mechanistic approach to modelling ozone tolerance and detoxification capacity. The development and integration of mechanistic ozone detoxification modules in models, such as that proposed by Plöchl et al., could potentially lead to improved model accuracy [69].

The view that $\mathrm{O}_{3}$ flux should be the metric of exposure in $\mathrm{O}_{3}$ effect modelling is also supported by the fact that $\mathrm{O}_{3}$ flux accounted for the different levels of exposure in treatments dominated by peaks in concentration, versus those characterised by a consistent background level, for the majority of physiological parameters. Flux is therefore likely to perform well as a predictor of physiological response across different world regions which are currently experiencing divergent trends in the pattern of $\mathrm{O}_{3}$ exposure [10-12].

Limitations of this study need to be considered when interpreting and applying the results. Calculated values of $\mathrm{O}_{3}$ flux were not verified by leaf-level measurements of gas flux through stomata. However, the decision to apply the multiplicative $\mathrm{DO}_{3} \mathrm{SE}$ model in this study was based on the fact that fluxes produced by this model have previously been evaluated in several independent studies which have demonstrated the model's predictive capability [19,21,22,70-72]. A further limitation is that estimates of the onset of leaf senescence were based on leaf chlorophyll content, which would have represented both the chlorophyll loss resulting from leaf injury, as well as chlorophyll loss relating to senescence. In addition, the analysis is based on only one crop species and two cultivars. As the variation in yield response to $\mathrm{O}_{3}$ exhibited by different crops, and different cultivars within the same crop species, is well established [2,73], caution must be used when extrapolating results presented here to other wheat cultivars and crops. It should however be noted that the observation in this study that no $\mathrm{O}_{3}$ effect on photosynthesis could be observed in young wheat leaves-indicating the senescence response is more important than direct effects on photosynthesis-is supported by previous work in other wheat cultivars [55] and by other experimental work in soybean [53,54]. Considerations when applying the results presented in this study, particularly when attempting to up-scale modelled responses from the leaf to canopy level, include the fact that the response observed in the wheat flag leaf may differ from the responses of lower-canopy leaves, and exposure to $\mathrm{O}_{3}$ during early seedling and leaf development may also alter the sensitivity to $\mathrm{O}_{3}$ observed in the flag leaf.

In conclusion, this study has shown that current approaches for modelling $\mathrm{O}_{3}$ effects on leaf longevity and photosynthesis in crops have some limitations and are not fully supported by the experimental data presented here. Model functions representing $\mathrm{O}_{3}$-induced senescence must allow for parameterisation of the timing of senescence onset and rate of senescence, if inter-cultivar variation in response is to be accurately simulated. Further research aimed at understanding the mechanistic 'trigger' of $\mathrm{O}_{3}$-induced senescence should be a priority, as this understanding may allow for the development of a more effective mechanism in models for inducing the senescence response. The results also suggest an age-dependency in the response of photosynthesis to $\mathrm{O}_{3}$-which is not currently fully considered in modelling methods-and indicate that acceleration of senescence is more important than direct effects of $\mathrm{O}_{3}$ on photosynthesis in determining final $\mathrm{O}_{3}$-induced yield loss, at $\mathrm{O}_{3}$ concentrations that crops are likely to be exposed to on a day-to-day basis. Building functions that can accurately represent the $\mathrm{O}_{3}$-induced senescence effect in crops should therefore be the priority for $\mathrm{O}_{3}$ effect modellers.

\section{Materials and Methods}

\subsection{Experimental Site and Treatments}

Both experiments that provided data for this study took place at the $\mathrm{CEH}$ air pollution exposure facility in Abergwyngregyn, North Wales $\left(53.2^{\circ} \mathrm{N}, 4.0^{\circ} \mathrm{W}\right)$. The two experiments were conducted independently and differ in terms of the number of cultivars and treatments, however, the experimental 
design was similar across both years and the same protocols for physiological measurements were applied. Data was therefore subsequently pooled across the two years to produce a more robust dataset. In 2015, two European wheat cultivars (Triticum aestivum L., 'Mulika' and 'Skyfall') were exposed to $\mathrm{O}_{3}$ for 82 days. In 2016, only the more $\mathrm{O}_{3}$-sensitive cultivar, 'Skyfall', was used and was exposed for 92 days. Timelines for sowing, emergence, $\mathrm{O}_{3}$ exposure, and harvest in both experiments are presented in Figure A1 of the Appendix A. In both experiments, plants were grown in 25-litre containers $(40 \mathrm{~cm} \times$ $35 \mathrm{~cm} \times 38 \mathrm{~cm}$ ) filled with John Innes No.3 compost (Westland Horticulture Limited, Huntingdon, UK), and soil was inoculated shortly after sowing with microbial communities using a soil slurry taken from a nearby wheat field. Seeds were sown in rows $7 \mathrm{~cm}$ apart at a density of $\sim 260$ seedlings per square metre, which aligns with recommended seedling density for field conditions [74]. Four containers per cultivar-treatment combination were planted and placed alongside each other, producing a canopy of 144 plants per cultivar-treatment combination. In both years, ammonium nitrate fertiliser was applied once mid-season (80 kg/ha). In 2015, fungicide ('Unix', cyprodinil, $1.6 \mathrm{~kg} / \mathrm{ha}$-Syngenta, Bracknell, UK) was applied once and insecticide (pyrethrum, $1 \mathrm{~mL} / \mathrm{L}$-Bayer, Monheim Am Rhein, Germany) applied three times. In 2016, fungicide was applied twice (1st application: Trifloxystrobin, $0.12 \mathrm{~g} / \mathrm{L}$-Bayer, Mondheim Am Rhein, Gernany; tebuconazole, $0.125 \mathrm{~g} / \mathrm{L}$-Bayer, Mondheim Am Rhein, Germany; 2nd application: cyprodinil, $2.25 \mathrm{~g} / \mathrm{L}$-Syngenta, Bracknell, UK) and insecticide applied once (thiachloprid, $0.15 \mathrm{~g} / \mathrm{L}$-Bayer, Mondheim Am Rhein, Germany).

Ozone exposure took place within 'solar domes', hemispherical glass domes three metres in diameter and two metres in height, described previously [59,75]. Air entering domes was carbon-filtered to remove $\mathrm{O}_{3}$ and other air pollutants (i.e., $\mathrm{NO}_{\mathbf{X}}$ and $\mathrm{SO}_{2}$ ), and the solar dome site is an area with some of the lowest $\mathrm{NO}_{\mathrm{X}}$ and $\mathrm{SO}_{2}$ emissions in the country and is not downwind of any major sources [76], minimising any other pollutants that could have entered the domes after filtration. Following filtration, a precision-controlled quantity supplied by an $\mathrm{O}_{3}$ generator (Dryden Aqua G11, Edinburgh, UK) linked to an oxygen concentrator (Sequal 10, Pure O2, Manchester, UK), was added to incoming air. Injection concentrations were determined by a computer-controlled $\mathrm{O}_{3}$ injection system (Lab VIEW, version 8.6, National Instruments, Austin, TX, USA). Air within domes was circulated at a rate of two air changes per minute, and the $\mathrm{O}_{3}$ concentration within each dome was recorded on a 30-min cycle using two $\mathrm{O}_{3}$ analysers of matched calibration (Envirotech API 400A, St Albans, UK). Exposure profiles for each treatment are presented in Figure 5. Treatments spanned a range of seasonal mean concentrations and represented different $\mathrm{O}_{3}$ exposure patterns, representing potential future profiles of increasing background or decreasing peak $\mathrm{O}_{3}$. In 2015, four treatments consisted of a low night-time background level, with high peaks during the day, classified as 'peak' treatments, while the other four treatments comprised of consistent concentrations with only small peaks, classified as 'background' treatments. In 2016, all treatments were 'peak' in profile. Although $\mathrm{O}_{3}$ treatments were not replicated, numerous studies have established the statistical validity of conducting unreplicated experiments using the solar dome facility $[56,77,78]$, and previous work has shown that no solar dome effect on air or leaf temperature is detectable [79].

Climatic conditions fluctuated naturally in the solar domes according to ambient conditions. Air temperature, photosynthetically active radiation (PAR), relative humidity, and wind speed were monitored in one solar dome during both experiments using an automatic weather station (Skye instruments Ltd, Llandridod Wells, UK) to obtain data for stomatal flux modelling. Plants were well-watered throughout, and soil moisture content was continuously monitored in selected plant containers to a depth of $10 \mathrm{~cm}$ using Theta Probes (Delta-T Devices Ltd., Cambridge, UK). 


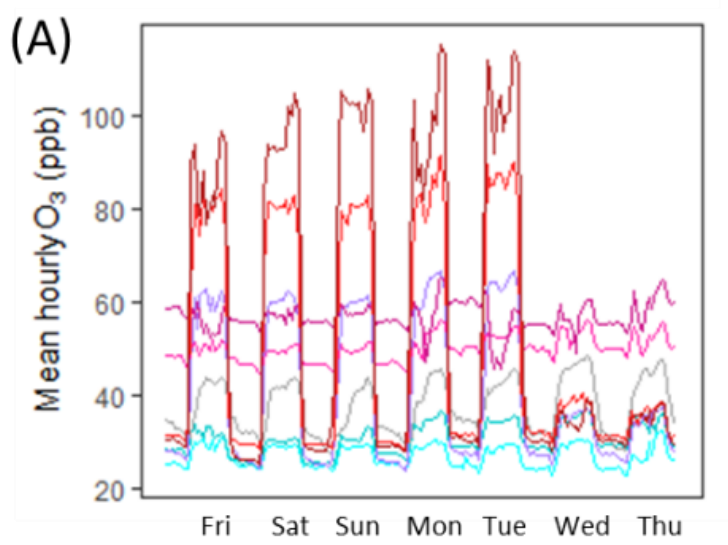

\section{Ozone treatment}

- LB

- LP

- $\mathrm{MB}$

- MP

- $\mathrm{HB}$

- VHB

- HP

- VHP

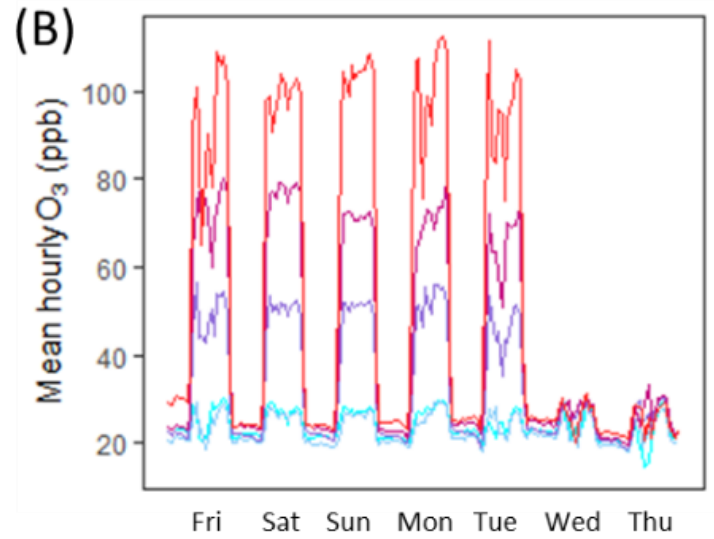

Ozone treatment

- LP1

- LP2

- MP

- HP

- VHP

Figure 5. Average hourly $\mathrm{O}_{3}$ exposure concentrations in (A) 2015 and (B) 2016. Values are shown for a one-week period, averaged over the entirety of each growing season. Each treatment has been categorised based on the 24-h mean exposure (Low, Medium, High, Very High) and the characteristic profile of exposure (peak or background). Treatments were applied five days out of seven to mimic real-world $\mathrm{O}_{3}$ exposure.

\subsection{Leaf Chlorophyll and Gas Exchange Measurements}

Chlorophyll content was measured non-destructively as an index (chlorophyll content index, CCI) using CCM-200 and CCM-200+ instruments (Opti-sciences, Hudson, NH, USA). A regression line fit to paired measurements was used to standardise observations made using the two instruments. In 2015, 684 measurements were made over 70 days; in 2016, 105 measurements were made over 22 days.

To assess the effect of $\mathrm{O}_{3}$ on photosynthetic capacity and $g_{s t o}$, response curves of net photosynthetic rate $(A)$ to intercellular $\mathrm{CO}_{2}$ concentration $\left(\mathrm{C}_{\mathrm{i}}\right)$, i.e., $A-\mathrm{C}_{\mathrm{i}}$ curves, were constructed using a portable infrared gas analyser (Li-Cor 6400XT; LI-COR Biosciences, Lincoln, NE, USA). In 2015, measurements were made in the two lowest $\mathrm{O}_{3}$ treatments at the beginning of exposure (20-26 May). Further measurements in the two lowest treatments (LB and LP) and two high $\mathrm{O}_{3}$ treatments (VHB and VHP) were made in the mid-season (8-17 June) and late-season (16-24 July). Measurements were made in the youngest fully expanded leaf of randomly selected plants (represented by the flag leaf) from 28th May onwards. In 2016, four sets of $A-C_{i}$ curve measurements were made at approximate two-weekly intervals spanning 6 June to 29 July. Measurements in 2016 were made in all treatments at each of the time intervals, except for the final measurement set in late July, when plants in HP and VHP treatments were too senesced for measurements to take place. All 2016 measurements were made in the flag leaf. For both years, four $A-C_{i}$ measurements were made per treatment and per cultivar at each timepoint, and leaves were tagged following measurement so that the same leaf could be measured throughout the season. 
All response curve measurements were conducted at a selected light saturation (minimum photosynthetic photon flux density $=1500 \mu \mathrm{mol} \mathrm{m}{ }^{-2} \mathrm{~s}^{-1}$, LED light source), and sample chamber relative humidity was maintained between 50 and $80 \%$. Photosynthetic rate and $g_{\text {sto }}$ were allowed to stabilise in the leaf chamber at ambient $\mathrm{CO}_{2}\left(400 \mu \mathrm{mol} \mathrm{mol}^{-1}\right)$. The $A-\mathrm{C}_{\mathrm{i}}$ curve was constructed by measuring $A$ at a minimum of nine air $\mathrm{CO}_{2}$ concentrations, ranging from ca. 50 to $2000 \mu \mathrm{mol} \mathrm{mol}^{-1}$. $A_{\text {sat }}$ and associated $g_{\text {sto }}$ values were determined from the ambient $\mathrm{CO}_{2}$ measurements $\left(400 \mu \mathrm{mol} \mathrm{mol}{ }^{-1}\right)$ from each $A-C_{\mathrm{i}}$ curve.

Additional measurements of $A_{\text {sat }}$ and associated $g_{\text {sto }}$ were made in 2016 over six days (16 June, 1 July, 8 July, 14 July, 20 July, 26 July). Measurements were made at ambient $\mathrm{CO}_{2}$ concentration $\left(400 \mu \mathrm{mol} \mathrm{mol}^{-1}\right)$ under the same light and relative humidity conditions as described above.

\subsection{Derivation of $V_{c \max }$ and $J_{\max }$}

Maximum rate of carboxylation $\left(V_{c \max }\right)$ and maximum rate of electron transport $\left(J_{\max }\right)$ were derived from $A-C_{\mathrm{i}}$ curves using the estimating utility and methodology described by Sharkey et al. [80]. Leaf temperature and atmospheric pressure were the input parameters, which were measured using the Licor 6400XT simultaneously with all photosynthesis measurements. $V_{c \max }$ and $J_{\max }$ values calculated from curves were adjusted to $25^{\circ} \mathrm{C}$.

The $V_{\text {cmax }}$ dataset was extended by applying the 'one-point method' of deriving $V_{c m a x}$ from $A_{\text {sat }}$ as described by De Kauwe et al. [81]. Estimation of $V_{\text {cmax }}$ when only $A_{\text {sat }}$ is known using the one-point method relies on the assumption that photosynthetic rate at ambient $\mathrm{CO}_{2}$ is rubisco-limited [81]. As the measurements of $A$ at $400 \mu \mathrm{mol} \mathrm{mol}{ }^{-1} \mathrm{CO}_{2}$ in the measured $A-\mathrm{C}_{\mathrm{i}}$ curves typically fell within the rubisco-limited section of the curve (i.e., before the transition point), this assumption was thought to be likely to hold true for the two cultivars used in this study. The one-point method also assumes, in the absence of a known daytime respiration rate $\left(R_{d a y}\right)$, that $R_{d a y}$ can be estimated as $1.5 \%$ of $V_{c m a x}$. $V_{\text {cmax }}$ was calculated from $A_{\text {sat }}$ using the following equation:

$$
V_{c m a x}=A_{s a t} *\left(\frac{C_{i}+K_{m}}{C_{i}-\Gamma *}-0.015\right)
$$

where $K_{m}$ is the Michaelis-Menten constant, given by:

$$
K_{m}=K_{c} *\left(1+\frac{O_{i}}{K_{O}}\right)
$$

The parameters $K_{c}$ (Michaelis-Menten constant for $\mathrm{CO}_{2}$ ), $K_{O}$ (Michaelis-Menten constant for $\mathrm{O}_{2}$ ) and $\Gamma^{*}\left(\mathrm{CO}_{2}\right.$ compensation point in the absence of mitochondrial respiration) were estimated at $25^{\circ} \mathrm{C}$ following the equations and constants published by Bernacchi et al. [82] describing their temperature dependence in the model species tobacco (Nicotiana tabacum, L.). Equations and constants used to derive these three parameters are listed in Table A2 of the Appendix A. $\mathrm{O}_{i}$ represents the intercellular concentration of $\mathrm{O}_{2}\left(210 \mathrm{mmol} \mathrm{mol}^{-1}\right)$ [81].

The robustness of the one-point method was evaluated by comparing $V_{c m a x}$ values calculated from a subset of the measured $A-C_{i}$ curves with the $V_{c m a x}$ values calculated from each corresponding $A_{\text {sat }}$ value (i.e., the $400 \mu \mathrm{mol} \mathrm{mol}{ }^{-1} \mathrm{CO}_{2}$ value from each $A-\mathrm{C}_{\mathrm{i}}$ curve). $V_{\text {cmax }}$ values derived using both methods were adjusted to $25^{\circ} \mathrm{C}$. A very close association was observed between $V_{\text {cmax }}$ values derived using the two methods (Figure 6, adjusted $r^{2}=0.95, p<0.001$ ), indicating that the one-point method is robust for the cultivars used in this study. $V_{c \max }$ values derived using the one-point method were therefore pooled with $A-\mathrm{C}_{\mathrm{i}}$-derived $V_{c m a x}$ values for analysis, and the potential error introduced through the use of two different derivation methods was accounted for in the statistical analysis by including - in model selection - an explanatory variable describing the derivation method (explained in more detail in Section 4.7.3). 


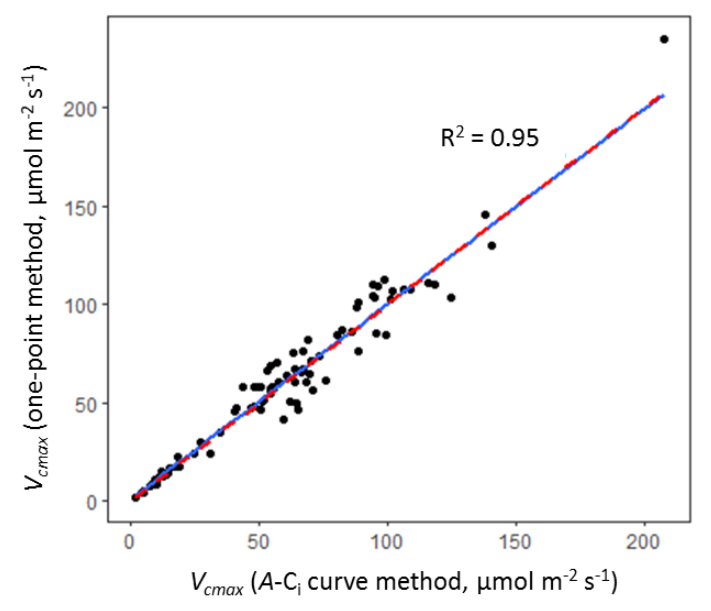

Figure 6. Plot of $V_{\text {cmax }}$ values derived from $A-C_{\mathrm{i}}$ curves versus $V_{c m a x}$ values calculated using the one-point method [75] from the corresponding $A_{\text {sat }}$ value extracted from each curve (A at $400 \mu \mathrm{mol}$ $\left.\mathrm{mol}^{-1} \mathrm{CO}_{2}\right)$. The blue line represents the linear regression model fit $\left(p<0.001\right.$, adjusted $r^{2}=0.95$; line equation, $\mathrm{y}=0.99 \mathrm{x}+1.33$ ). The red dashed line represents the line of $\mathrm{x}=\mathrm{y}$. Data for this comparison comprise a subset of the $A-C_{\mathrm{i}}$ curve dataset used in this study.

\subsection{Modelling $\mathrm{O}_{3}$ Flux}

Stomatal $\mathrm{O}_{3}$ flux to the flag leaf was modelled in each treatment for both years to derive a measure of exposure that accounted for the environmental influence on $\mathrm{O}_{3}$ uptake and could be tracked over time. Flux was modelled using the multiplicative $g_{\text {sto }}$ module of the $\mathrm{DO}_{3} \mathrm{SE}$ model [18], which has a published parameterisation for European wheat $[49,50,83]$ and has been applied previously to model $\mathrm{O}_{3}$ flux to this crop [22,84]. A summary of the $\mathrm{DO}_{3} \mathrm{SE}$ algorithms and parameters used in this study are presented in Section A1 of the Appendix.

Ozone flux for wheat is accumulated above a detoxification threshold of six in the $\mathrm{DO}_{3} \mathrm{SE}$ methodology (producing the $\mathrm{POD}_{6}$ SPEC flux metric, species-specific phytotoxic $\mathrm{O}_{3}$ dose above a threshold of $6 \mathrm{mmol} \mathrm{m}^{-2}$ PLA s${ }^{-1}$ - previously known as the $\mathrm{POD}_{6}$, with "SPEC" referring to the species-specific version of the $\mathrm{DO}_{3} \mathrm{SE}$ model) [83], as this threshold has produced the closest correlation between POD and wheat yield in previous experiments [50]. However, as thresholds of physiological effect in wheat have been far less studied, the $\mathrm{POD}_{0} \mathrm{SPEC}$ (where no threshold for accumulation is applied, previously known as the $\mathrm{POD}_{0}$ ) was also calculated, in order to avoid assuming a threshold of effect. Modelled $\mathrm{POD}_{0}$ SPEC and $\mathrm{POD}_{6} \mathrm{SPEC}$ for 2015 and $2016 \mathrm{O}_{3}$ treatments are shown in Figure 7.

\subsection{Alignment of Physiological Observations with $\mathrm{O}_{3}$ Flux, and Calculation of Mean Flux Exposure (Mean Daily $\left.P O D_{0} S P E C\right)$}

Each physiological observation (CCI, $A_{\text {sat }}, V_{\text {cmax }}, J_{\max }, g_{\text {sto }}$ ) was aligned with the treatment-specific accumulated $\mathrm{POD}_{0} \mathrm{SPEC}$ and $\mathrm{POD}_{6} \mathrm{SPEC}$ on the day of measurement and at the exact time of measurement, wherever this data was available (referred to hereafter in this paper as 'accumulated $\mathrm{POD}_{0} \mathrm{SPEC}$ ' and 'accumulated $\mathrm{POD}_{6} \mathrm{SPEC}^{\prime}$ ). This was done to allow the impact of real-time $\mathrm{O}_{3}$ flux exposure on physiology to be analysed. The mean daily $\mathrm{POD}_{0} \mathrm{SPEC}$ (i.e., the average accumulation of flux per day, $\mathrm{mmol} \mathrm{m}^{-2}$ PLA day ${ }^{-1}$ ) was also calculated for each $\mathrm{O}_{3}$ treatment to act as a metric of mean exposure intensity. Mean daily $\mathrm{POD}_{0}$ SPEC values for each $\mathrm{O}_{3}$ treatment are presented in the results section in Table 1 . Mean daily $\mathrm{POD}_{0} \mathrm{SPEC}$ was calculated as the average of daily $\mathrm{POD}_{0} \mathrm{SPEC}$ accumulation from $A_{\text {start }}$ until the modelled onset of senescence. 

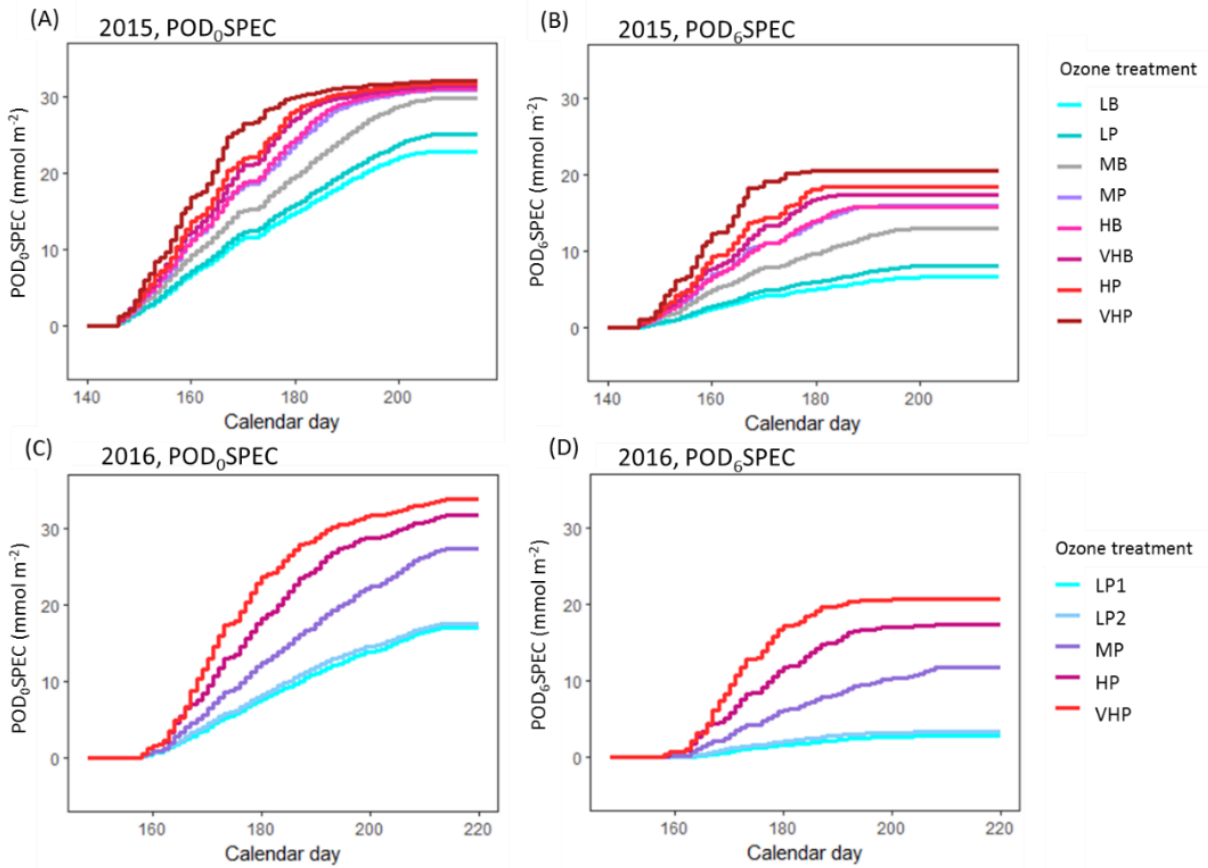

Figure 7. Modelled $\mathrm{O}_{3}$ flux over time in the different $\mathrm{O}_{3}$ treatments. (A) $\mathrm{POD}_{0} \mathrm{SPEC}$ in 2015,

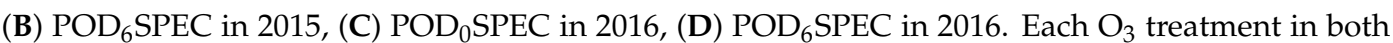
years was categorised based on the 24-h mean exposure ( $\mathrm{L}=$ low, $\mathrm{M}=$ medium, $\mathrm{H}=$ high, $\mathrm{VH}=$ very high) and the characteristic profile of exposure ( $\mathrm{P}=$ peak, $\mathrm{B}=$ background $)$.

\subsection{Data Standardisation}

The two experiments had different sowing and harvest calendars. In order to compare timings across the two experiments, time was therefore standardised by calculating thermal time from plant emergence onwards (daily mean temperature sum $>0{ }^{\circ} \mathrm{C}$ ). Physiological data was also standardised, by conversion from raw to relative values. This was done to account for differences in instrument calibration between years, and to account for differences in beginning of season 'baseline' physiology between cultivars. Relative values for the physiological observations were calculated by deriving a reference value for each parameter $\left(\mathrm{CCI}, A_{s a t}, V_{c \max }, J_{\max }, g_{\text {sto }}\right)$ and each cultivar-year combination (i.e., Mulika in 2015, Skyfall in 2015, Skyfall in 2016). The reference value-calculated as the 90th percentile value of all observations, spanning the whole season and all treatments-was used as the baseline for calculating relative change. Skyfall CCI data from 2016 comprised too few data points for the derivation of an individual reference value, 2016 and 2015 CCI data for Skyfall was therefore combined to produce a single reference value for Skyfall, as CCI data for Skyfall was found to not significantly differ by year ( $p=0.06$ in regression model). A comparison of CCI data for Skyfall measured in 2015 and 2016 can be found in Section A3 of the Appendix.

\subsection{Statistical Analysis}

Statistical analysis was conducted in R version 3.3.2 [85], and either involved linear regression or linear mixed models (LMMs) using the package lme4 v1.17. Model selection was by AIC (Akaike Information Criterion). The model with the lowest AIC was considered the 'best' model of those fitted, and models differing in $<2$ AIC units from the best model were defined as having little empirical support [86]. Wherever relevant, a random factor describing solar dome number was included in models to account for multiple measurements made within domes, and unique pot ID was a random factor when analysis involved multiple measurements made from the same pot. $p$-values were obtained for terms in the optimal models using the R package lmerTest, v2.0-33 [87]. Assumptions of normality and even spread of residuals were checked using residual plots and data were transformed 
where necessary. Four key analyses were conducted as part of this study and are described in more detail below.

\subsubsection{Identification of $\mathrm{O}_{3}$ Treatments with Significantly Accelerated Senescence}

Flag leaf $\mathrm{CCI}$ data was analysed in all $\mathrm{O}_{3}$ treatments to test for accelerated senescence. Each elevated $\mathrm{O}_{3}$ treatment was paired in turn with the control treatment for that experiment, and the significance of the thermal time/mean daily $\mathrm{POD}_{0} \mathrm{SPEC}$ interaction term was tested using LMMs. Control treatments were defined as the lowest in terms of mean daily $\mathrm{POD}_{0} \mathrm{SPEC}$ and comprised of treatment LB for the 2015 experiment and treatment LP2 for the 2016 experiment.

\subsubsection{Analysis of $\mathrm{O}_{3}$ Effect on the Timing of Senescence Onset and Completion}

The impact of $\mathrm{O}_{3}$ on leaf senescence onset and completion was examined using regression models fitted to each of the $2015 \mathrm{O}_{3}$ treatments (separately for the two cultivars). It was not possible to conduct this analysis for 2016, as 2016 CCI measurements only spanned 22 days. Regression models comprised of relative CCI as the dependent variable and thermal time as the independent variable, and the shape of response was determined by comparing linear, quadratic, and cubic models. The best model for each $\mathrm{O}_{3}$ treatment was then used to determine i) thermal time at leaf senescence onset, ii) thermal time at senescence completion, and iii) the post-anthesis curve integral (i.e., area under the curve), as shown in Figure 8. Thermal time at senescence onset was aligned with the accumulated $\mathrm{POD}_{0} \mathrm{SPEC}$ at that time for each $\mathrm{O}_{3}$ treatment, to identify the accumulated flux 'trigger' values for senescence onset.

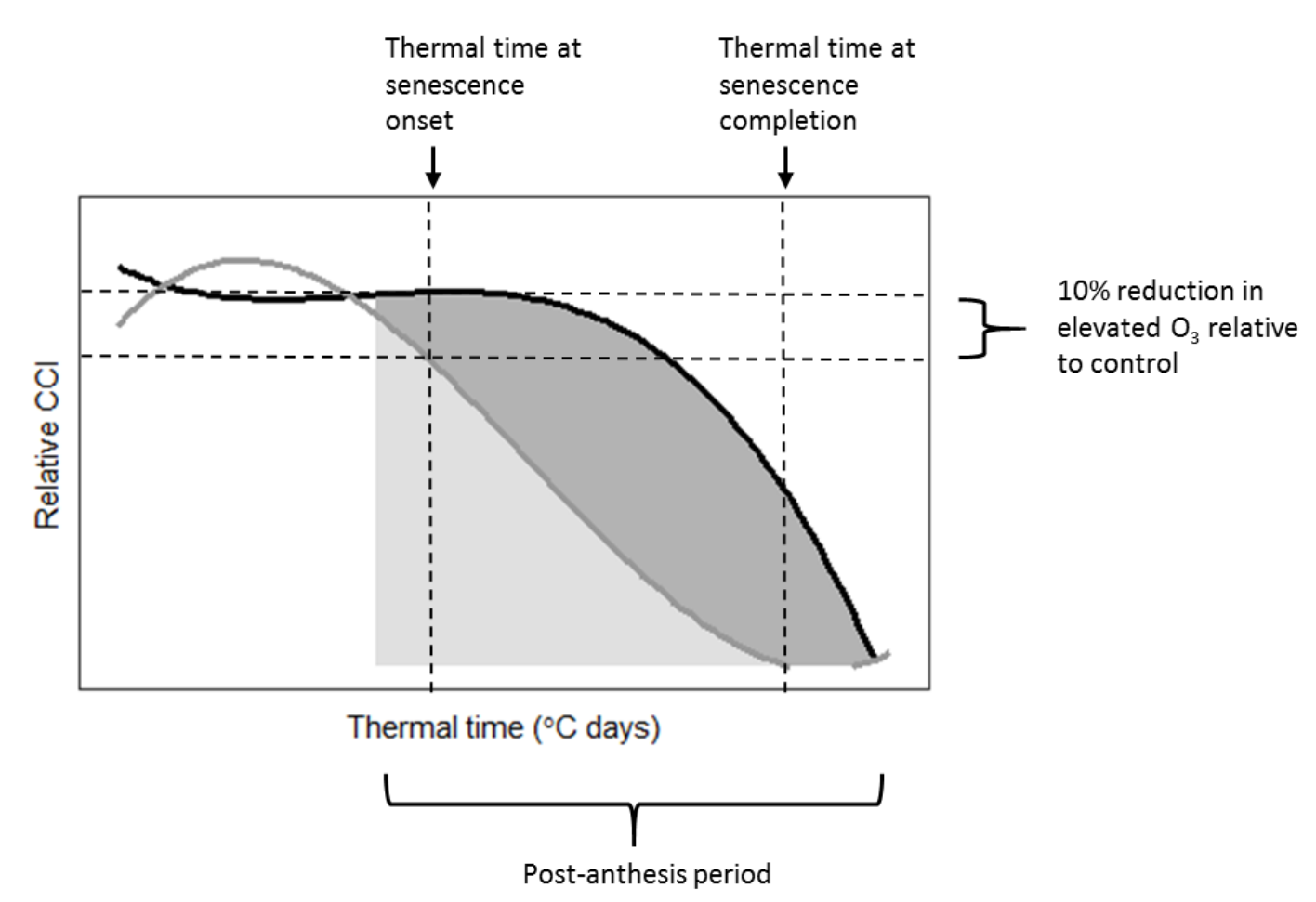

Figure 8. Summary of methods used to derive: i) Thermal time at leaf senescence onset, defined as a $10 \%$ reduction in relative CCI in the elevated treatment (grey line) relative to the control (black line); ii) thermal time at senescence completion, defined by the $\mathrm{x}$-abscissa of the treatment regression line; iii) the post-anthesis integral of the regression curve, indicated on the plot as shaded regions (Post-anthesis period in $2015=1142{ }^{\circ} \mathrm{C}$ days onwards). Diagram not to scale.

\subsubsection{Analysis of Relative Timing of $\mathrm{O}_{3}$ Effects on Different Aspects of Physiology}

The effect of accumulated $\mathrm{POD}_{0} \mathrm{SPEC}$ on CCI, $A_{\text {sat }}, V_{c \max }, J_{\max }$, and $g_{\text {sto }}$ during successive periods of the growing season was analysed, to identify when $\mathrm{O}_{3}$ began to influence physiology. The range of 
thermal time spanned by flag leaf physiological measurements was divided into six thermal time-bins of equal width. The effect of accumulated POD ${ }_{0}$ SPEC on each parameter, within each time-bin and for each cultivar-year combination, was analysed by comparing model fit with and without accumulated $\mathrm{POD}_{0}$ SPEC as an explanatory variable. An additional explanatory variable was included in model selection for $V_{c m a x}$, describing the derivation method (i.e., A-Ci curve or one-point method).

\subsubsection{Comparison of Flux and Concentration-Based $\mathrm{O}_{3}$ Exposure Metrics for Predicting} Physiological Response

Accumulated $\mathrm{POD}_{0}$ SPEC, accumulated POD 6 SPEC, 24-h mean concentration, and AOT40 (accumulated $\mathrm{O}_{3}>40 \mathrm{ppb}$ during daylight hours) were compared in their ability to predict the response of CCI, $A_{s a t}, V_{c \max }, J_{\max }$, and $g_{\text {sto }}$ during the 5 th thermal time-bin. The 5th time-bin was selected for this analysis as most physiological parameters exhibited a response to $\mathrm{O}^{3}$ exposure during this time. For each physiological parameter, LMMs constructed with each of the metrics of $\mathrm{O}_{3}$ exposure were compared for model fit. An explanatory variable describing whether $\mathrm{O}_{3}$ had been administered as a 'peak' or 'background' profile was also included in model selection, to test whether the $\mathrm{O}_{3}$ metric that produced the best model fit also accounted for different patterns of exposure.

Author Contributions: Conceptualization, S.O., D.P., G.M. and L.E.; methodology, S.O., G.M., D.P., F.H. and H.H.; software, D.G.; formal analysis, S.O.; investigation, S.O., D.P., G.M., L.E. and P.B.; writing-original draft preparation, S.O.; writing-review and editing, S.O., D.P., G.M., L.E., P.B., F.H. and H.H.; visualization, S.O.; supervision, G.M. and L.E.; funding acquisition, G.M., L.E. and D.P.

Funding: We would like to thank the Natural Environment Research Council of the United Kingdom (grant number DTG NE/L 501645/1) and the AXA Post-Doctoral Fellowships Research Fund for funding this work.

Acknowledgments: Many thanks to Aled Williams and Elwyn Jones for their help in maintaining the solar dome experimental facility.

Conflicts of Interest: The authors declare no conflict of interest. The funders had no role in the design of the study; in the collection, analyses, or interpretation of data; in the writing of the manuscript, or in the decision to publish the results.

\section{Appendix A}

\section{A1. Summary of $\mathrm{DO}_{3}$ SE Model Methodology and Parameterisation used for Calculating $\mathrm{O}_{3}$ Flux}

$\mathrm{DO}_{3} \mathrm{SE}$ estimates hourly stomatal conductance to $\mathrm{O}_{3}\left(g_{\text {sto_O}}, \mathrm{mmol} \mathrm{O}_{3} \mathrm{~m}^{-2} \mathrm{PLA} \mathrm{s}^{-1}\right)$ using the following algorithm $[18,19]$, which takes a species-specific maximum $g_{\text {sto }}$ value $\left(g_{\max }\right)$ and modifies it by a series of factors relating to environmental variables:

$$
g_{\text {sto_O3 }}=g_{\max } *\left[\min \left(f_{\text {phen, }}, f_{\text {O3 }}\right)\right] * f_{\text {light }} * \max \left\{f_{\text {min }},\left(f_{\text {temp }} * f_{V P D} * f_{S W P}\right)\right.
$$

where $f_{\text {phen }}, f_{\mathrm{O} 3}, f_{\text {light }}, f_{\text {temp }}, f_{\mathrm{VPD}}$, and $f_{\mathrm{SWP}}$ represent the influence of phenology, $\mathrm{O}_{3}$, photosynthetically active radiation (PAR), air temperature, vapour pressure deficit (VPD), and soil

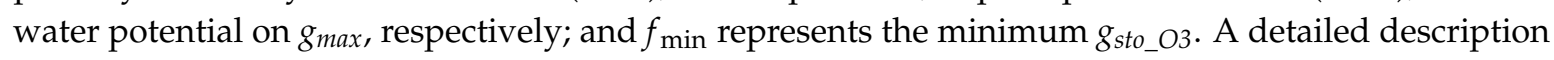
of how parameters relating to the different $\mathrm{DO}_{3} \mathrm{SE} f$-functions are derived can be found in the CLRTAP mapping manual [83].

Stomatal flux of $\mathrm{O}_{3}-F_{S T}\left(\mathrm{nmol} \mathrm{m}^{-2} \mathrm{PLA} \mathrm{s}^{-1}\right)$ - is calculated following the assumption that the concentration of $\mathrm{O}_{3}$ at the top of the canopy represents a reasonable estimate of the concentration at the upper surface of the laminar layer of the flag leaf, using the following algorithm:

$$
F_{S T}=c\left(z_{i}\right) * g_{\text {sto_O3 }} * \frac{r_{c}}{r_{b}+r_{c}}
$$

where $c\left(z_{i}\right)$ is the concentration of $\mathrm{O}_{3}$ at the top of the canopy of height $i(\mathrm{~m})$, and $r_{c}$ and $r_{b}$ represent the leaf surface and quasi-laminar resistances, respectively. The derivation of $r_{c}$ and $r_{b}$ based on leaf dimension and wind speed are described in detail in the CLRTAP mapping manual [83]. Once hourly 
$F_{S T}$ has been derived, the hourly $F_{S T}$ is then accumulated over a species-specific accumulation period using the following equation:

$$
P O D_{Y} S P E C=\sum\left[\left(F_{S T}-Y\right) *\left(\frac{3600}{10^{6}}\right)\right.
$$

where PODYSPEC stands for the species-specific phytotoxic $\mathrm{O}_{3}$ dose ( $\mathrm{mmol} \mathrm{m}{ }^{-2}$ PLA), the term $\left(3600 / 10^{6}\right)$ converts to hourly fluxes and to $\mathrm{mmol} \mathrm{m}^{-2}$ PLA, and the value $Y$ represents the threshold of flux above which negative $\mathrm{O}_{3}$ effects may occur (i.e., the detoxification capacity). In this study the flux accumulation period was defined by the life of the flag leaf.

Model parameters used in the calculation of $\mathrm{O}_{3}$ flux in this study are presented in Table A1. The same parameterisation was applied for both wheat cultivars and both years. The parameterisation follows those that have been published for European wheat $[49,50,83]$, with the exception of the parameters $f_{\text {phen_e }}$ and $f_{\text {phen_h }}$, which were calibrated so that the period of flux accumulation aligned approximately with the observed life of the flag leaf in both experiments; and the two parameters which define the $f_{\mathrm{O} 3}$ function (the flux at senescence onset, and the exponent of the senescence function), which were calibrated so that the end of flux accumulation in the highest $\mathrm{O}_{3}$ treatments in 2015 and 2016 aligned approximately with the observed date of leaf senescence in those treatments.

Table A1. Parameters applied in $\mathrm{DO}_{3} \mathrm{SE}$ to derive the species-specific accumulated $\mathrm{O}_{3}$ flux $\left(\mathrm{POD}_{0} \mathrm{SPEC}\right.$ and POD $_{6}$ SPEC) for the 2015 and 2016 experiments.

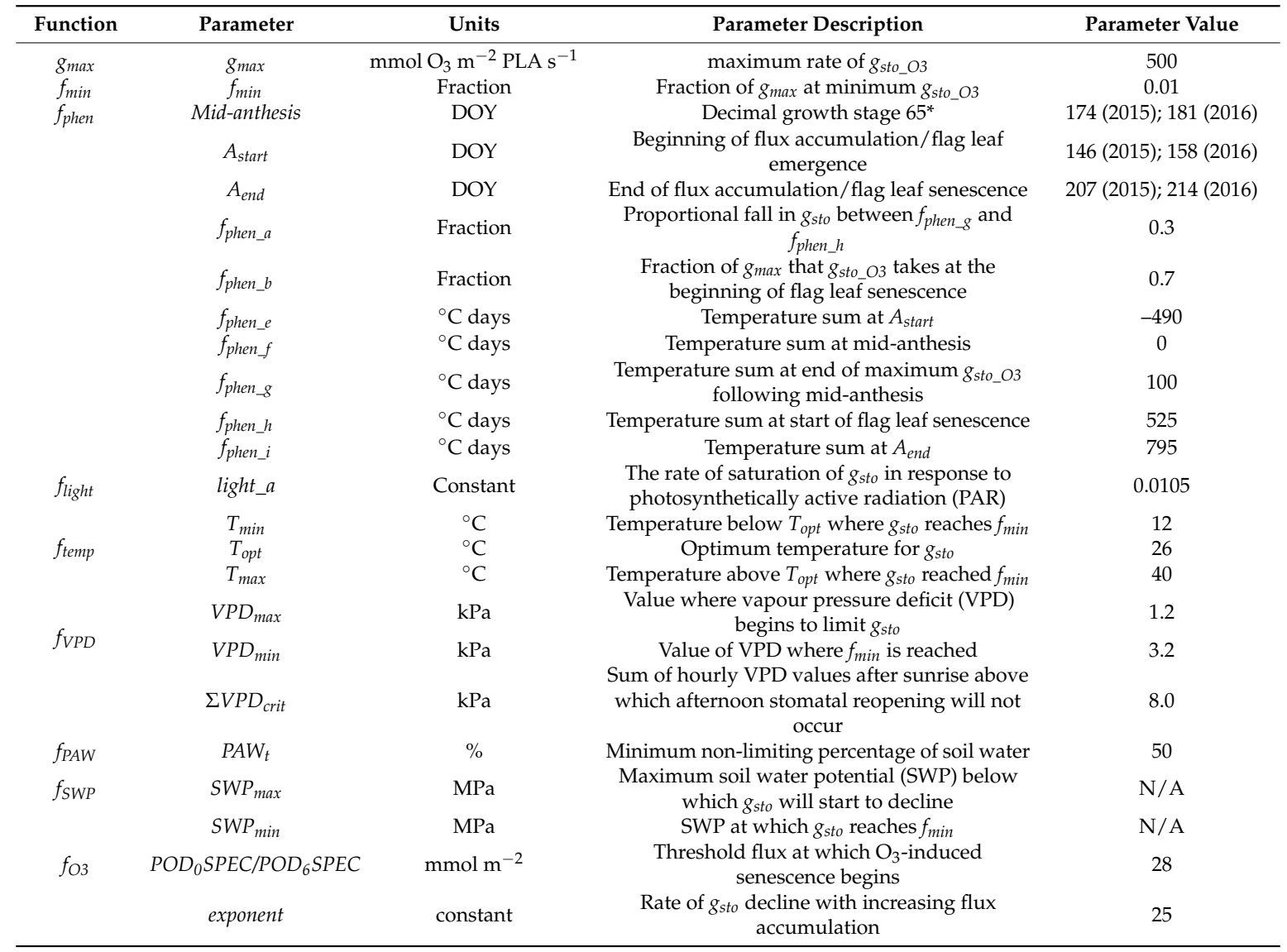




\section{A2. Timelines for 2015 and 2016 Experiments}

(A) 2015 Experiment

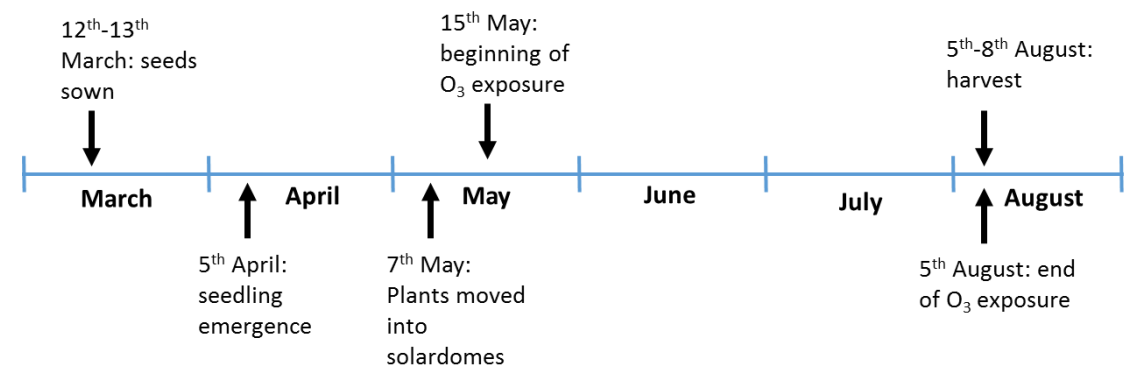

(B) 2016 Experiment

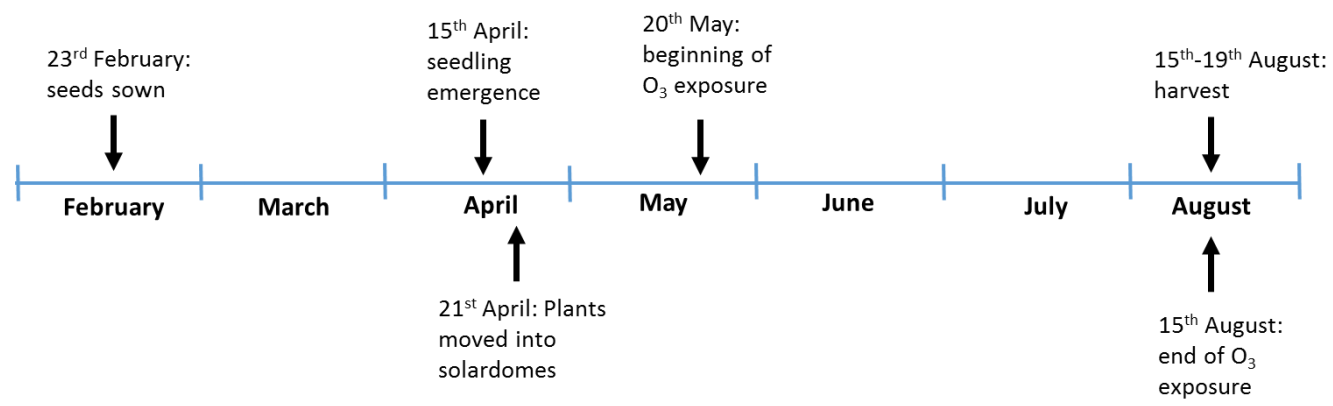

Figure A1. Timeline for sowing, seedling emergence, $\mathrm{O}_{3}$ exposure, and plant harvest for (A) the 2015 experiment and (B) the 2016 experiment.

A3. Comparisons of Chlorophyll Content Index (CCI) Measurements in Skyfall Made in 2015 and 2016

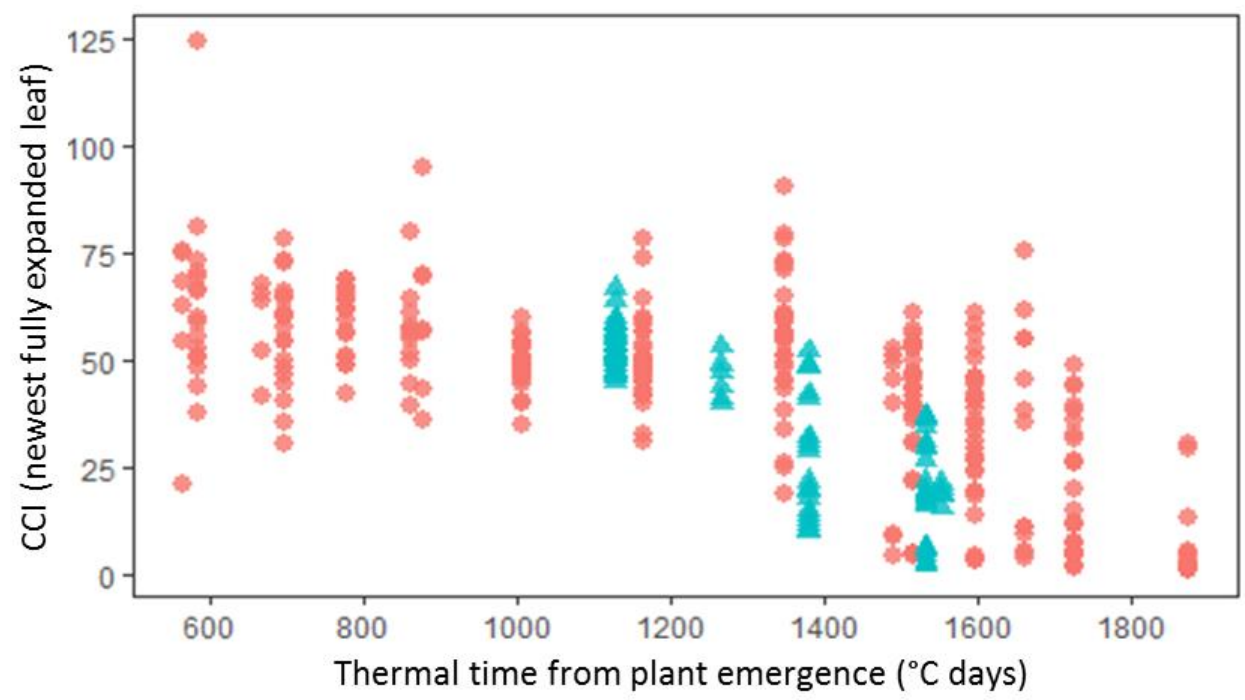

Figure A2. Chlorophyll content index (CCI) measurements made in the cultivar Skyfall in 2015 (red circles) and 2016 (blue triangles). The 2016 observations align approximately with the 2015 observations recorded during the same thermal time period. 
A4. Physiological Observations Aligned with Accumulated POD $_{6}$ SPEC

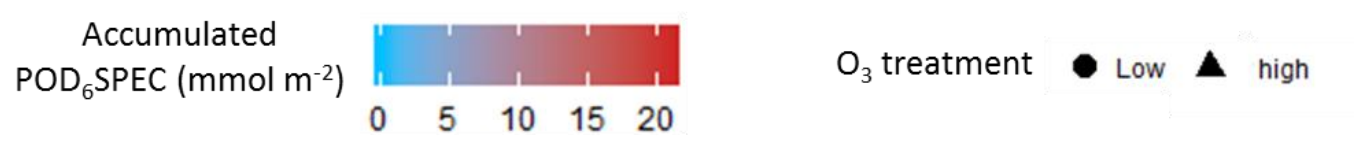

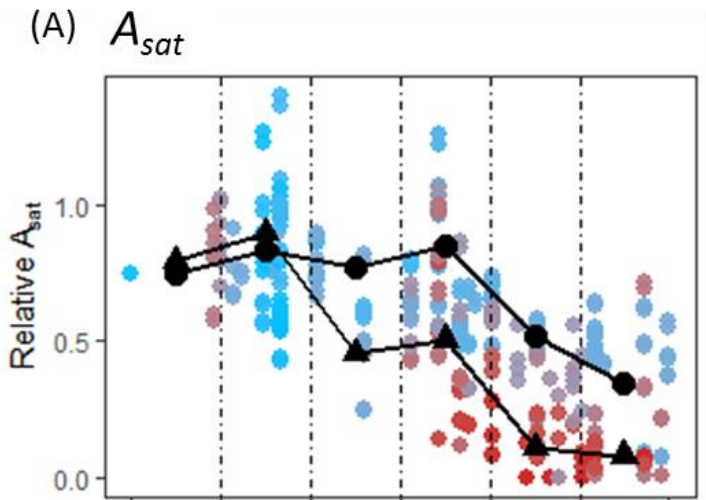

(C) $J_{\max }$

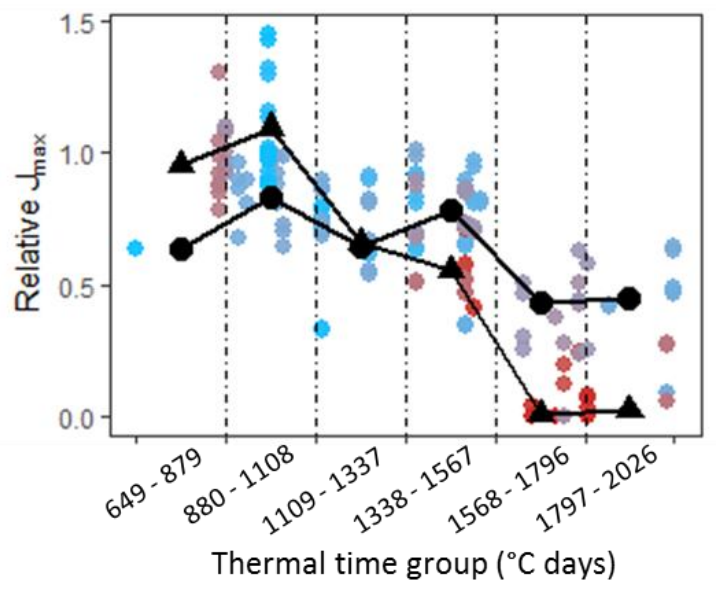

(B) $\quad V_{c m a x}$

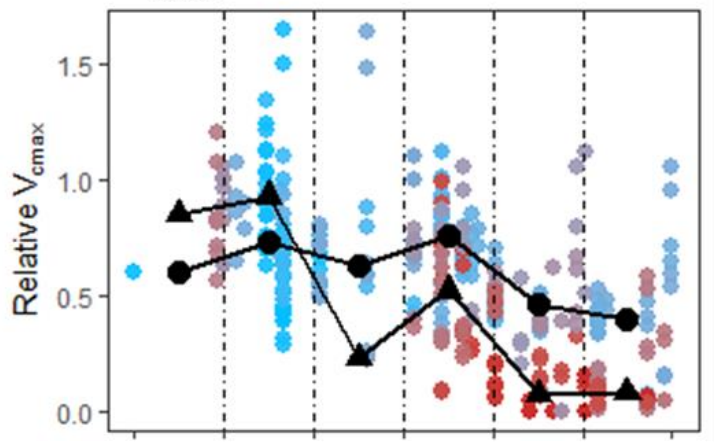

(D) $g_{\text {sto }}$

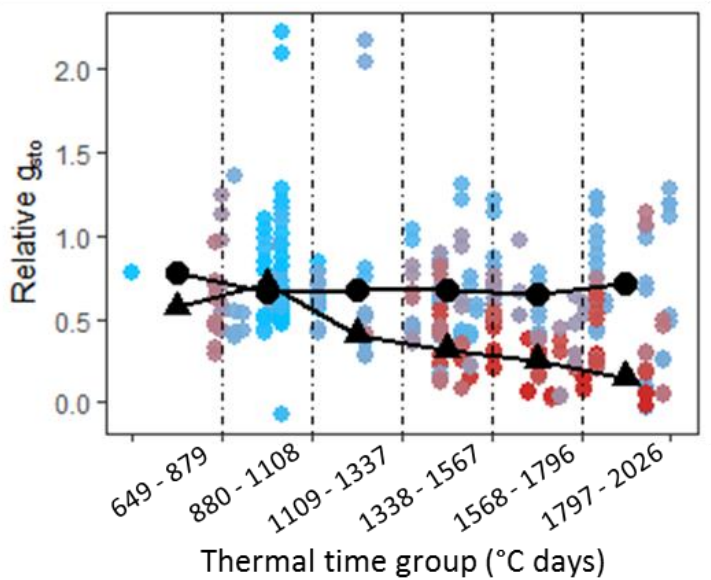

Figure A3. Flag leaf data for (A) $\mathrm{A}_{\text {sat }},(\mathbf{B}) \mathrm{V}_{\mathrm{cmax}},(\mathbf{C}) \mathrm{J}_{\max }$, and (D) $\mathrm{g}_{\text {sto }}$, combined across all cultivar-year combinations. The hue of each data point corresponds to the accumulated $\mathrm{POD}_{6} \mathrm{SPEC}$ at the moment of measurement. Vertical lines on the plots indicate the divisions between thermal time groups. Mean values of physiological parameters in low $\mathrm{O}_{3}$-treated plants (averaged across 2015 LB and 2015 LP2 treatments) and high $\mathrm{O}_{3}$-treated plants (averaged across $2015 \mathrm{VHP}$ and 2016 VHP treatments) are shown as black data points on the plots.

\section{A5. Equations Used in the Derivation of $V_{c \max }$ Using the One-Point Method}

Table A2. Equations used to derive the Michaelis-Menten constant for $\mathrm{CO}_{2}\left(\mathrm{~K}_{\mathrm{C}}\right)$, the Michaelis-Menten constant for $\mathrm{O}_{2}\left(\mathrm{~K}_{\mathrm{O}}\right)$, and the $\mathrm{CO}_{2}$ compensation point in the absence of mitochondrial respiration $\left(\Gamma^{*}\right)$.

\begin{tabular}{lll}
\hline Parameter & Unit & Equation Used in Derivation \\
\hline$K_{C}$ & $\mu \mathrm{mol} \mathrm{mol}-1$ & $404.9 * \exp \left(\frac{79403\left(T_{K}-298.15\right)}{298.15 * R * T_{K}}\right)$ \\
$K_{O}$ & $\mathrm{mmol} \mathrm{mol}^{-1}$ & $278.4 * \exp \left(\frac{36380\left(T_{K}-298.15\right)}{298.15 * R * T_{K}}\right)$ \\
$\Gamma^{*}$. & $\mu \mathrm{mol} \mathrm{mol}-1$ & $42.75 * \exp \left(\frac{37830\left(T_{K}-298.15\right)}{298.15 * R * T_{K}}\right)$ \\
\hline$T_{K}=$ leaf temperature in Kelvin; $R=$ universal gas constant, $8.314 \mathrm{~J} \mathrm{~mol}^{-1} \mathrm{~K}^{-1}$.
\end{tabular}

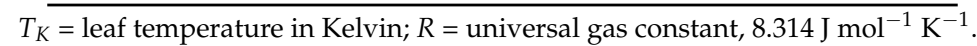




\section{A6. Statistical Summary of LMM Analysis on Physiological Parameters}

Table A3. Outcome of linear mixed models (LMM) analysis investigating which $\mathrm{O}_{3}$ treatments in 2015 and 2016 exhibited an early decline in leaf chlorophyll (CCI) relative to the control treatments.

\begin{tabular}{clll}
\hline $\begin{array}{c}\text { Cultivar-Year } \\
\text { Combination }\end{array}$ & $\begin{array}{l}\text { Ozone } \\
\text { Treatment Code }\end{array}$ & $\begin{array}{l}\text { Accelerated Senescence in } \\
\text { Treatment Relative to } \\
\text { Control? }{ }^{* *}\end{array}$ & $\begin{array}{l}\text { Mean POD } \text { SPEC}^{*} \text { Thermal } \\
\text { Time Interaction Variable } \\
p \text {-Value }\end{array}$ \\
\hline Mulika, 2015 & LP & No & n.e. \\
& MB & No & n.e. \\
& MP & No & n.e. \\
& HB & No & n.e. \\
& HP & No & n.e. \\
& VHB & Yes & $p<0.001$ \\
Skyfall, 2015 & VHP & Yes & $p<0.001$ \\
& MB & Yes & $p<0.0001$ \\
& MP & Yes & $p<0.0001$ \\
& HB & Yes & $p<0.0001$ \\
& HP & Yes & $p<0.0001$ \\
& VHB & Yes & $p<0.0001$ \\
& VHP & Yes & $p<0.0001$ \\
& LP1 & No & n.e. \\
& MP & Yes & $p<0.0001$ \\
& HP & Yes & $p<0.05$ \\
& VHP & Yes & $p<0.0001$ \\
\hline
\end{tabular}

** Control treatment was defined as the lowest treatment in terms of mean daily $\mathrm{POD}_{0} \mathrm{SPEC}$ for each season (i.e., treatment LB in 2015 and treatment LP2 in 2016).; n.e. = no significant effect at $p<0.05$.

Table A4. Statistics summarising the effect of accumulated $\mathrm{POD}_{0} \mathrm{SPEC}$ on flag leaf chlorophyll (CCI) in the six thermal time groups.

\begin{tabular}{|c|c|c|c|c|}
\hline $\begin{array}{l}\text { Cultivar-Year } \\
\text { Combination. }\end{array}$ & $\begin{array}{c}\text { Thermal Time-Bin } \\
\left({ }^{\circ} \text { Cdays }\right)\end{array}$ & $\begin{array}{c}\text { Number of } \\
\text { Observations }\end{array}$ & $\begin{array}{c}\text { POD }_{0} \text { SPEC } \\
\text { Variable } p \text {-Value }\end{array}$ & Direction of Effect \\
\hline \multirow[t]{6}{*}{ Mulika, 2015} & $649-879$ & 44 & n.e. & \\
\hline & $880-1108$ & 18 & n.e. & \\
\hline & 1109-1337 & 16 & n.e. & \\
\hline & $1338-1567$ & 34 & n.e. & \\
\hline & 1568-1796 & 52 & $p<0.01$ & - ve \\
\hline & 1797-2026 & 17 & n.e. & \\
\hline \multirow[t]{6}{*}{ Skyfall, 2015} & $649-879$ & 36 & $p<0.05$ & $+\mathrm{ve}$ \\
\hline & $880-1108$ & 16 & n.e. & \\
\hline & 1109-1337 & 16 & $p<0.05$ & - ve \\
\hline & $1338-1567$ & 38 & $p<0.05$ & - ve \\
\hline & 1568-1796 & 38 & $p<0.001$ & - ve \\
\hline & 1797-2026 & 16 & n.e. & \\
\hline \multirow[t]{6}{*}{ Skyfall, 2016} & $649-879$ & 0 & & \\
\hline & 880-1108 & 0 & & \\
\hline & 1109-1337 & 50 & $p<0.001$ & - ve \\
\hline & $1338-1567$ & 55 & $p<0.01$ & - ve \\
\hline & 1568-1796 & 0 & & \\
\hline & 1797-2026 & 0 & & \\
\hline
\end{tabular}


Table A5. Statistics summarising the effect of accumulated $\mathrm{POD}_{0} \mathrm{SPEC}$ on flag leaf $\mathrm{A}_{\text {sat }}$.

\begin{tabular}{|c|c|c|c|c|}
\hline $\begin{array}{l}\text { Cultivar-Year } \\
\text { Combination }\end{array}$ & $\begin{array}{c}\text { Thermal Time-Bin } \\
\left({ }^{\circ} \text { Cdays }\right)\end{array}$ & $\begin{array}{c}\text { Number of } \\
\text { Observations }\end{array}$ & $\begin{array}{c}\text { POD }_{0} \text { SPEC } \\
\text { Variable } p \text {-Value }\end{array}$ & Direction of Effect \\
\hline \multirow[t]{6}{*}{ Mulika, 2015} & $649-879$ & 9 & n.e. & \\
\hline & 880-1108 & 6 & n.e. & \\
\hline & 1109-1337 & 0 & & \\
\hline & $1338-1567$ & 0 & & \\
\hline & 1568-1796 & 16 & $p<0.05$ & - ve \\
\hline & $1797-2026$ & 0 & & \\
\hline \multirow[t]{6}{*}{ Skyfall, 2015} & $649-879$ & 8 & n.e. & \\
\hline & 880-1108 & 8 & $p<0.01$ & + ve \\
\hline & 1109-1337 & 0 & & \\
\hline & $1338-1567$ & 0 & & \\
\hline & $1568-1796$ & 7 & $p<0.05$ & - ve \\
\hline & 1797-2026 & 8 & $p<0.001$ & - ve \\
\hline \multirow[t]{6}{*}{ Skyfall, 2016} & $649-879$ & 0 & & \\
\hline & 880-1108 & 52 & $p<0.001$ & + ve \\
\hline & $1109-1337$ & 28 & $p<0.05$ & - ve \\
\hline & $1338-1567$ & 118 & $p<0.05$ & - ve \\
\hline & $1568-1796$ & 56 & $p<0.001$ & \\
\hline & 1797-2026 & 66 & $p<0.001$ & \\
\hline
\end{tabular}

n.e. $=$ no significant effect at $p<0.05$.

Table A6. Statistics summarising the effect of accumulated $\mathrm{POD}_{0} \mathrm{SPEC}$ on flag leaf $\mathrm{V}_{\mathrm{cmax}}$.

\begin{tabular}{|c|c|c|c|c|}
\hline $\begin{array}{l}\text { Cultivar-Year } \\
\text { Combination }\end{array}$ & $\begin{array}{c}\text { Thermal Time-Bin } \\
\left({ }^{\circ} \text { Cdays }\right)\end{array}$ & $\begin{array}{c}\text { Number of } \\
\text { Observations }\end{array}$ & $\begin{array}{c}\text { POD }_{0} \text { SPEC } \\
\text { Variable } p \text {-Value }\end{array}$ & Direction of Effect \\
\hline \multirow[t]{6}{*}{ Mulika, 2015} & $649-879$ & 9 & n.e. & \\
\hline & 880-1108 & 6 & n.e. & \\
\hline & 1109-1337 & 0 & & \\
\hline & $1338-1567$ & 0 & & \\
\hline & $1568-1796$ & 16 & $p<0.01$ & - ve \\
\hline & 1797-2026 & 0 & & \\
\hline \multirow[t]{6}{*}{ Skyfall, 2015} & $649-879$ & 8 & n.e. & \\
\hline & 880-1108 & 8 & n.e. & \\
\hline & 1109-1337 & 0 & & \\
\hline & $1338-1567$ & 0 & & \\
\hline & $1568-1796$ & 7 & n.e. & \\
\hline & 1797-2026 & 8 & $p<0.001$ & - ve \\
\hline \multirow[t]{6}{*}{ Skyfall, 2016} & $649-879$ & 0 & & \\
\hline & 880-1108 & 54 & $p<0.001$ & $+\mathrm{ve}$ \\
\hline & $1109-1337$ & 28 & n.e. & \\
\hline & $1338-1567$ & 118 & n.e. & \\
\hline & $1568-1796$ & 56 & $p<0.001$ & - ve \\
\hline & 1797-2026 & 66 & $p<0.001$ & - ve \\
\hline
\end{tabular}

n.e. $=$ no significant effect at $p<0.05$.

Table A7. Statistics summarising the effect of accumulated $\mathrm{POD}_{0} \mathrm{SPEC}$ on flag leaf $\mathrm{J}_{\max }$.

\begin{tabular}{ccccc}
\hline $\begin{array}{c}\text { Cultivar-Year } \\
\text { Combination }\end{array}$ & $\begin{array}{c}\text { Thermal Time-Bin } \\
\left({ }^{\circ} \text { Cdays) }\right.\end{array}$ & $\begin{array}{c}\text { Number of } \\
\text { Observations }\end{array}$ & $\begin{array}{c}\text { POD }_{\mathbf{0}} \text { SPEC } \\
\text { Variable } \boldsymbol{p} \text {-Value }\end{array}$ & Direction of Effect \\
\hline Mulika, 2015 & $649-879$ & 9 & $p<0.05$ & + ve \\
& $880-1108$ & 6 & n.e. & \\
$1109-1337$ & 0 & & - ve \\
& $1338-1567$ & 0 & $p<0.01$ & \\
& $1568-1796$ & 16 & & \\
& $1797-2026$ & 0 & & \\
\hline
\end{tabular}


Table A7. Cont.

\begin{tabular}{ccccc}
\hline $\begin{array}{c}\text { Cultivar-Year } \\
\text { Combination }\end{array}$ & $\begin{array}{c}\text { Thermal Time-Bin } \\
\left({ }^{\circ} \text { Cdays }\right)\end{array}$ & $\begin{array}{c}\text { Number of } \\
\text { Observations }\end{array}$ & $\begin{array}{c}\text { POD } \text { SPEC } \\
\text { Variable } p \text {-Value }\end{array}$ & Direction of Effect \\
\hline Skyfall, 2015 & $649-879$ & 8 & n.e. \\
& $880-1108$ & 8 & n.e. \\
$1109-1337$ & 0 & & \\
& $1338-1567$ & 0 & $p<0.05$ & - ve \\
& $1568-1796$ & 7 & $p<0.001$ & - ve \\
Skyfall, 2016 & $1797-2026$ & 8 & n.e. & n.e. \\
& $649-879$ & 0 & n.e. & \\
& $880-1108$ & 16 & & \\
& $1109-1337$ & 28 & n.e. \\
\hline
\end{tabular}

n.e. $=$ no significant effect at $p<0.05$.

Table A8. Statistics summarising the effect of accumulated $\mathrm{POD}_{0} \mathrm{SPEC}$ on flag leaf $\mathrm{g}_{\text {sto }}$.

\begin{tabular}{|c|c|c|c|c|}
\hline $\begin{array}{l}\text { Cultivar-Year } \\
\text { Combination }\end{array}$ & $\begin{array}{c}\text { Thermal Time-Bin } \\
\left({ }^{\circ} \text { Cdays }\right)\end{array}$ & $\begin{array}{c}\text { Number of } \\
\text { Observations }\end{array}$ & $\begin{array}{c}\text { POD }_{0} \text { SPEC } \\
\text { Variable } p \text {-Value }\end{array}$ & Direction of Effect \\
\hline \multirow[t]{6}{*}{ Mulika, 2015} & $649-879$ & 9 & n.e. & \\
\hline & 880-1108 & 6 & n.e. & \\
\hline & 1109-1337 & 0 & & \\
\hline & $1338-1567$ & 0 & & \\
\hline & $1568-1796$ & 15 & $p<0.05$ & - ve \\
\hline & 1797-2026 & 0 & & \\
\hline \multirow[t]{6}{*}{ Skyfall, 2015} & $649-879$ & 8 & n.e. & \\
\hline & 880-1108 & 59 & $p<0.01$ & +ve \\
\hline & 1109-1337 & 28 & & \\
\hline & $1338-1567$ & 116 & & \\
\hline & $1568-1796$ & 63 & n.e. & \\
\hline & 1797-2026 & 74 & $p<0.001$ & - ve \\
\hline \multirow{6}{*}{ Skyfall, 2016} & $649-879$ & 8 & & \\
\hline & 880-1108 & 7 & n.e. & \\
\hline & 1109-1337 & 0 & n.e. & \\
\hline & $1338-1567$ & 0 & $p<0.01$ & - ve \\
\hline & $1568-1796$ & 7 & $p<0.001$ & - ve \\
\hline & $1797-2026$ & 8 & $p<0.001$ & - ve \\
\hline
\end{tabular}

n.e. $=$ no significant effect at $p<0.05$.

\section{References}

1. Feng, Z.; Kobayashi, K. Assessing the impacts of current and future concentrations of surface ozone on crop yield with meta-analysis. Atmos. Environ. 2009, 43, 1510-1519. [CrossRef]

2. Mills, G.; Buse, A.; Gimeno, B.; Bermejo, V.; Holland, M.; Emberson, L.; Pleijel, H. A synthesis of AOT40-based response functions and critical levels of ozone for agricultural and horticultural crops. Atmos. Environ. 2007, 41, 2630-2643. [CrossRef]

3. Finlayson-Pitts, B.J.; Pitts, J.N. Atmospheric chemistry of tropospheric ozone formation-Scientific and regulatory implications. J. Air Waste Manag. Assoc. 1993, 43, 1091-1100. [CrossRef]

4. Royal Society. Ground-Level Ozone in the 21st Century: Future Trends, Impacts and Policy Implications; Royal Society: London, UK, 2008.

5. Vingarzan, R. A review of surface ozone background levels and trends. Atmos. Environ. 2004, 38, 3431-3442. [CrossRef]

6. Volz, A.; Kley, D. Evaluation of the Montsouris series of ozone measurements made in the 19th century. Nature 1988, 332, 240-242. [CrossRef] 
7. Cooper, O.R.; Parrish, D.D.; Ziemke, J.; Cupeiro, M.; Galbally, I.E.; Gilge, S.; Horowitz, L.; Jensen, N.R.; Lamarque, J.F.; Naik, V.; et al. Global distribution and trends if tropospheric ozone: An observation-based review. Elem. Sci. Anthr. 2014, 2, 29. [CrossRef]

8. Parrish, D.D.; Lamarque, J.F.; Naik, V.; Horowitz, L.; Shindell, D.T.; Staehelin, J.; Derwent, R.; Cooper, O.R.; Tanimoto, H.; Volz-Thomas, A.; et al. Long-term changes in lower tropospheric baseline ozone concentrations at northern mid-latitudes. Atmos. Chem. Phys. 2012, 12, 11485-11504. [CrossRef]

9. IPCC. Annex II: Climate System Scenario Tables. In Climate Change 2013: The Physical Science Basis. Contribution of Working Group I to the Fifth Assessment Report of the Intergovernmental Panel on Climate Change; Stocker, T.F., Qin, D., Plattner, G.K., Tignor, M., Allen, S.K., Boschung, J., Nauels, A., Xia, Y., Bex, V., Midgley, P.M., Eds.; Cambridge University Press: Cambridge, UK, 2013.

10. Lei, H.; Wuebbles, D.J.; Liang, X.Z. Projected risk of high ozone episodes in 2050. Atmos. Environ. 2012, 59, 567-577. [CrossRef]

11. Xu, X.; Lin, W.; Wang, T.; Yan, P.; Tang, J.; Meng, Z.; Wang, Y. Long-term trend of surface ozone at a regional background station in eastern China 1991-2006: Enhanced variability. Atmos. Chem. Phys. 2008, 8, $2595-2607$. [CrossRef]

12. Paoletti, E.; De Marco, A.; Beddows, D.C.; Harrison, R.M.; Manning, W.J. Ozone levels in European and USA cities are increasing more than at rural sites, while peak values are decreasing. Environ. Pollut. 2014, 192, 295-299. [CrossRef] [PubMed]

13. Avnery, S.; Mauzerall, D.L.; Liu, J.F.; Horowitz, L.W. Global crop yield reductions due to surface ozone exposure: 2. Year 2030 potential crop production losses and economic damage under two scenarios of $\mathrm{O}_{3}$ pollution. Atmos. Environ. 2011, 45, 2297-2309. [CrossRef]

14. Van Dingenen, R.; Dentener, F.J.; Raes, F.; Krol, M.C.; Emberson, L.; Cofala, J. The global impact of ozone on agricultural crop yields under current and future air quality legislation. Atmos. Environ. 2009, 43, 604-618. [CrossRef]

15. Wang, X.; Mauzerall, D.L. Characterizing distributions of surface ozone and its impact on grain production in China, Japan and South Korea: 1990 and 2020. Atmos. Environ. 2004, 38, 4383-4402. [CrossRef]

16. Ghude, S.D.; Jena, C.K.; Kumar, R.; Kulkarni, S.H.; Chate, D.M. Impact of emission mitigation on ozone-induced wheat and rice damage in India. Curr. Sci. 2016, 110, 1452-1458.

17. Emberson, L.D.; Pleijel, H.; Ainsworth, E.A.; Van den Berg, M.; Ren, W.; Osborne, S.; Mills, G.; Pandey, D.; Dentener, F.; Büker, P.; et al. Ozone effects on crops and consideration in crop models. Eur. J. Agron. 2018, 100, 19-34. [CrossRef]

18. Emberson, L.; Simpson, D.; Tuovinen, J.; Ashmore, M.; Cambridge, H. Towards a Model of Ozone Deposition and Stomatal Uptake over Europe; EMEP MSC-W Note; Norwegian Meteorological Institute: Oslo, Norway, 2000.

19. Büker, P.; Morrissey, T.; Briolat, A.; Falk, R.; Simpson, D.; Tuovinen, J.P.; Alonso, R.; Barth, S.; Baumgarten, M.; Grulke, N.; et al. $\mathrm{DO}_{3} \mathrm{SE}$ modelling of soil moisture to determine ozone flux to forest trees. Atmos. Chem. Phys. 2012, 12, 726-735. [CrossRef]

20. Danielsson, H.; Karlsson, G.P.; Karlsson, P.E.; Pleijel, H.H. Ozone uptake modelling and flux-response relationships-An assessment of ozone-induced yield loss in spring wheat. Atmos. Environ. 2003, 37, 475-485. [CrossRef]

21. Emberson, L.; Wieser, G.; Ashmore, M. Modelling of stomatal conductance and ozone flux of Norway spruce: Comparison with field data. Environ. Pollut. 2000, 109, 393-402. [CrossRef]

22. González-Fernández, I.; Bermejo, V.; Elvira, S.; De La Torre, D.; González, A.; Navarrete, L.; Sanz, J.; Calvete, H.; García-Gómez, H.; López, A.; et al. Modelling ozone stomatal flux of wheat under mediterranean conditions. Atmos. Environ. 2013, 67, 149-160. [CrossRef]

23. Farquhar, G.D.; Caemmerer, S.V.; Berry, J.A. A biochemical model of photosynthetic $\mathrm{CO}_{2}$ assimilation in leaves of C3 species. Planta 1980, 149, 78-90. [CrossRef]

24. Leuning, R. Modelling stomatal behaviour and photosynthesis of Eucalyptus Grandis. Funct. Plant Biol. 1990, 17, 159-175. [CrossRef]

25. Ewert, F.; Porter, J.R. Ozone effects on wheat in relation to $\mathrm{CO}_{2}$ : Modelling short-term and long-term responses of leaf photosynthesis and leaf duration. Glob. Chang. Biol. 2000, 6, 735-750. [CrossRef]

26. Boote, K.J.; Jones, J.W.; White, J.W.; Asseng, S.; Lizaso, J.I. Putting mechanisms into crop production models. Plantcell Environ. 2013, 36, 1658-1672. [CrossRef] 
27. Martin, M.J.; Farage, P.K.; Humphries, S.W.; Long, S.P. Can the stomatal changes caused by acute ozone exposure be predicted by changes occurring in the mesophyll? A simplification for models of vegetation response to the global increase in tropospheric elevated ozone episodes. Funct. Plant Biol. 2000, 27, 211-219. [CrossRef]

28. Tao, F.; Feng, Z.; Tang, H.; Chen, Y.; Kobayashi, K. Effects of climate change, $\mathrm{CO}_{2}$ and $\mathrm{O}_{3}$ on wheat productivity in Eastern China, singly and in combination. Atmos. Environ. 2017, 153, 182-193. [CrossRef]

29. Schauberger, B.; Rolinksi, S.; Schaphoff, S.; Müller, C. Global historical soybean and wheat yield loss estimates from ozone pollution considering water and temperature as modifying effects. Agric. For. Meteorol. 2019, 265, 1-15. [CrossRef]

30. Heagle, A. Ozone and crop yield. Annu. Rev. Phytopathol. 1989, 27, 397-423. [CrossRef]

31. Jäger, H.J.; Unsworth, M.; De Temmerman, L.; Mathy, P. Effects of air pollution on agricultural crops in Europe: Results of the European open-top chambers project. Air Pollut. Res. Rep. 1992, 46, 46.

32. Feng, Z.; Kobayashi, K.; Ainsworth, E.A. Impact of elevated ozone concentration on growth, physiology, and yield of wheat (Triticum aestivum L.): A meta-analysis. Glob. Chang. Biol. 2008, 14, 2696-2708.

33. Fiscus, E.L.; Booker, F.L.; Burkey, K.O. Crop responses to ozone: Uptake, modes of action, carbon assimilation and partitioning. Plant Cell Environ. 2005, 28, 997-1011. [CrossRef]

34. Booker, F.; Muntifering, R.; McGrath, M.; Burkey, K.; Decoteau, D.; Fiscus, E.; Manning, W.; Krupa, S.; Chappelka, A.; Grantz, D. The ozone component of global change: Potential effects on agricultural and horticultural plant yield, product quality and interactions with invasive species. J. Integr. Plant Biol. 2009, 51, 337-351. [CrossRef]

35. Jolivet, Y.; Bagard, M.; Cabané, M.; Vaultier, M.-N.; Gandin, A.; Afif, D.; Dizengremel, P.; Le Thiec, D. Deciphering the ozone-induced changes in cellular processes: A prerequisite for ozone risk assessment at the tree and forest levels. Ann. For. Sci. 2016, 73, 923-943. [CrossRef]

36. Tiwari, S.; Grote, R.; Churkina, G.; Butler, T. Ozone damage, detoxification and the role of isoprenoids - new impetus for integrated models. Funct. Plant Biol. 2016, 43, 324-326. [CrossRef]

37. Lehnherr, B.; Grandjean, A.; Mächler, F.; Fuhrer, J. The effect of ozone in ambient air on ribulosebisphosphate carboxylase/oxygenase activity decreases photosynthesis and grain yield in wheat. J. Plant Physiol. 1987, 130, 189-200. [CrossRef]

38. Lehnherr, B.; Mächler, F.; Grandjean, A.; Fuhrer, J. The regulation of photosynthesis in leaves of field-grown spring wheat (Triticum aestivum L., cv Albis) at different levels of ozone in ambient air. Plant Physiol. 1988, 88, 1115-1119. [CrossRef]

39. Dann, M.S.; Pell, E.J. Decline of activity and quantity of ribulose bisphosphate carboxylase/oxygenase and net photosynthesis in ozone-treated potato foliage. Plant Physiol. 1989, 91, 427-432. [CrossRef]

40. Farage, P.; Long, $\mathrm{S}$. An in vivo analysis of photosynthesis during short-term $\mathrm{O}_{3}$ exposure in three contrasting species. Photosynth. Res. 1995, 43, 11-18. [CrossRef]

41. Farage, P.K.; Long, S.P.; Lechner, E.G.; Baker, N.R. The sequence of change within the photosynthetic apparatus of wheat following short-term exposure to ozone. Plant Physiol. 1991, 95, 529-535. [CrossRef]

42. Burkart, S.; Bender, J.; Tarkotta, B.; Faust, S.; Castagna, A.; Ranieri, A.; Weigel, H.J. Effects of ozone on leaf senescence, photochemical efficiency and grain yield in two winter wheat cultivars. J. Agron. Crop Sci. 2013, 199, 275-285. [CrossRef]

43. Feng, Z.; Pang, J.; Kobayashi, K.; Zhu, J.; Ort, D.R. Differential responses in two varieties of winter wheat to elevated ozone concentration under fully open-air field conditions. Glob. Chang. Biol. 2011, 17, 580-591. [CrossRef]

44. Gelang, J.; Pleijel, H.; Sild, E.; Danielsson, H.; Younis, S.; Selldén, G. Rate and duration of grain filling in relation to flag leaf senescence and grain yield in spring wheat (Triticum aestivum) exposed to different concentrations of ozone. Physiol. Plant. 2000, 110, 366-375. [CrossRef]

45. Grandjean, A.; Fuhrer, J. Growth and leaf senescence in spring wheat (Triticum aestivum) grown at different ozone concentrations in open-top field chambers. Physiol. Plant. 1989, 77, 389-394. [CrossRef]

46. Ojanperä, K.; Pätsikkä, E.; Yläranta, T. Effects of low ozone exposure of spring wheat on net $\mathrm{CO}_{2}$ uptake, Rubisco, leaf senescence and grain filling. New Phytol. 1998, 138, 451-460. [CrossRef]

47. Reich, P.B. Quantifying plant response to ozone: A unifying theory. Tree Physiol. 1987, 3, 63-91. [CrossRef] 
48. Deckmyn, G.; Op de Beeck, M.; Löw, M.; Then, C.; Verbeeck, H.; Wipfler, P.; Ceulemans, R. Modelling ozone effects on adult beech trees through simulation of defence, damage, and repair costs: Implementation of the CASIROZ ozone model in the ANAFORE forest model. Plant Biol. 2007, 9, 320-330. [CrossRef]

49. Grünhage, L.; Pleijel, H.; Mills, G.; Bender, J.; Danielsson, H.; Lehmann, Y.; Castell, J.F.; Bethenod, O. Updated stomatal flux and flux-effect models for wheat for quantifying effects of ozone on grain yield, grain mass and protein yield. Environ. Pollut. 2012, 165, 147-157. [CrossRef]

50. Pleijel, H.; Danielsson, H.; Emberson, L.; Ashmore, M.; Mills, G. Ozone risk assessment for agricultural crops in Europe: Further development of stomatal flux and flux-response relationships for European wheat and potato. Atmos. Environ. 2007, 41, 3022-3040. [CrossRef]

51. Meyer, U.; Köllner, B.; Willenbrink, J.; Krause, G.H.M. Effects of different ozone exposure regimes on photosynthesis, assimilates and thousand grain weight in spring wheat. Agric. Ecosyst. Environ. 2000, 78, 49-55. [CrossRef]

52. Maas, R.; Grennfelt, P. Towards Cleaner Air. Scientific Assessment Report 2016. EMEP Steering Body and Working Group on Effects of the Convention on Long-Range Transboundary Air Pollution; UNECE: Oslo, Norway, 2016.

53. Bernacchi, C.J.; Leakey, A.D.; Heady, L.E.; Morgan, P.B.; Dohleman, F.G.; McGrath, J.M.; Gillespie, K.M.; Wittig, V.E.; Rogers, A.; Long, S.P.; et al. Hourly and seasonal variation in photosynthesis and stomatal conductance of soybean grown at future $\mathrm{CO}_{2}$ and ozone concentrations for 3 years under fully open-air field conditions. Plantcell Environ. 2006, 29, 2077-2090.

54. Morgan, P.B.; Bernacchi, C.J.; Ort, D.R.; Long, S.P. An in vivo analysis of the effect of season-long open-air elevation of ozone to anticipated 2050 levels on photosynthesis in soybean. Plant Physiol. 2004, 135, 2348-2357. [CrossRef]

55. Reichenauer, T.; Goodman, B.; Kostecki, P.; Soja, G. Ozone sensitivity in Triticum durum and T. aestivum with respect to leaf injury, photosynthetic activity and free radical content. Physiol. Plant. 1998, 104, 681-686. [CrossRef]

56. Agathokleous, E.; Belz, R.G.; Calatayud, V.; De Marco, A.; Hoshika, Y.; Kitao, M.; Saitanis, C.J.; Sicard, P.; Paoletti, E.; Calabrese, E.J.; et al. Predicting the effect of ozone on vegetation via linear non-threshold (LNT), threshold and hormetic dose-response models. Sci. Total Environ. 2019, 649, 61-74. [CrossRef] [PubMed]

57. Mulholland, B.; Craigon, J.; Black, C.; Colls, J.; Atherton, J.; Landon, G. Impact of elevated atmospheric $\mathrm{CO}_{2}$ and $\mathrm{O}_{3}$ on gas exchange and chlorophyll content in spring wheat (Triticum aestivum L.). J. Exp. Bot. 1997, 48, 1853-1863. [CrossRef]

58. Wilkinson, S.; Davies, W.J. Drought, ozone, ABA and ethylene: New insights from cell to plant to community. Plantcell Environ. 2010, 33, 510-525. [CrossRef]

59. Mills, G.; Hayes, F.; Wilkinson, S.; Davies, W.J. Chronic exposure to increasing background ozone impairs stomatal functioning in grassland species. Glob. Chang. Biol. 2009, 15, 1522-1533. [CrossRef]

60. Wilkinson, S.; Davies, W.J. Ozone suppresses soil drying and abscisic acid (ABA)-induced stomatal closure via an ethylene-dependent mechanism. Plantcell Environ. 2009, 32, 949-959. [CrossRef] [PubMed]

61. Mills, G.; Hayes, F.; Simpson, D.; Emberson, L.; Norris, D.; Harmens, H.; Büker, P. Evidence of widespread effects of ozone on crops and (semi-)natural vegetation in Europe (1990-2006) in relation to AOT40-and flux-based risk maps. Glob. Chang. Biol. 2011, 17, 592-613. [CrossRef]

62. Pleijel, H.; Danielsson, H.; Ojanpera, K.; De Temmerman, L.; Hogy, P.; Badiani, M.; Karlsson, P.E. Relationships between ozone exposure and yield loss in European wheat and potato-A comparison of concentration- and flux-based exposure indices. Atmos. Environ. 2004, 38, 2259-2269. [CrossRef]

63. Hu, E.; Gao, F.; Xin, Y.; Jia, H.; Li, K.; Hu, J.; Feng, Z. Concentration- and flux-based ozone dose-response relationships for five poplar clones grown in North China. Environ. Pollut. 2015, 207, 21-30. [CrossRef]

64. Xu, Y.; Shang, B.; Yuan, X.; Feng, Z.; Calatayud, V. Relationships of $\mathrm{CO}_{2}$ assimilation rates with exposureand flux-based $\mathrm{O}_{3}$ metrics in three urban tree species. Sci. Total Environ. 2018, 613, 233-239. [CrossRef]

65. Ashmore, M. Assessing the future global impacts of ozone on vegetation. Plantcell Environ. 2005, $28,949-964$. [CrossRef]

66. Fuhrer, J.; Skarby, L.; Ashmore, M.R. Critical levels for ozone effects on vegetation in Europe. Environ. Pollut. 1997, 97, 91-106. [CrossRef]

67. Paoletti, E.; Manning, W.J. Toward a biologically significant and usable standard for ozone that will also protect plants. Environ. Pollut. 2007, 150, 85-95. [CrossRef] 
68. Tang, H.; Takigawa, M.; Liu, G.; Zhu, J.; Kobayashi, K. A projection of ozone-induced wheat production loss in China and India for the years 2000 and 2020 with exposure-based and flux-based approaches. Glob. Chang. Biol. 2013, 19, 2739-2752. [CrossRef]

69. Plöchl, M.; Lyons, T.; Ollerenshaw, J.; Barnes, J. Simulating ozone detoxification in the leaf apoplast through the direct reaction with ascorbate. Planta 2000, 210, 454-467. [CrossRef]

70. Büker, P.; Emberson, L.D.; Ashmore, M.R.; Cambridge, H.M.; Jacobs, C.M.; Massman, W.J.; Müller, J.; Nikolov, N.; Novak, K.; Oksanen, E.; et al. Comparison of different stomatal conductance algorithms for ozone flux modelling. Environ. Pollut. 2007, 146, 726-735. [CrossRef]

71. Fares, S.; Matteucci, G.; Mugnozza, G.S.; Morani, A.; Calfapietra, C.; Salvatori, E.; Fusaro, L.; Manes, F.; Loreto, F. Testing of models of stomatal ozone fluxes with field measurements in a mixed Mediterranean forest. Atmos. Environ. 2013, 67, 242-251. [CrossRef]

72. Pleijel, H.; Danielsson, H.; Vandermeiren, K.; Blum, C.; Colls, J.; Ojanperä, K. Stomatal conductance and ozone exposure in relation to potato tuber yield-Results from the European CHIP programme. Eur. J. Agron. 2002, 17, 303-317. [CrossRef]

73. Sawada, H.; Kohno, Y. Differential ozone sensitivity of rice cultivars as indicated by visible injury and grain yield. Plant Biol. 2009, 11, 70-75. [CrossRef] [PubMed]

74. AHDB. Wheat Growth Guide. Kenilworth, UK, 2015. Available online: https://cereals.ahdb.org.uk/media/ 185687/g66-wheat-growth-guide.pdf (accessed on 3 January 2015).

75. Hayes, F.; Williamson, J.; Mills, G. Species-specific responses to ozone and drought in six deciduous trees. Waterair Soil Pollut. 2015, 226, 156. [CrossRef]

76. NAEI. UK Emissions Interactive Map. 2018. Available online: http://naei.beis.gov.uk/data/gis-mapping (accessed on 6 May 2017).

77. Hayes, F.; Wagg, S.; Mills, G.; Wilkinson, S.; Davies, W. Ozone effects in a drier climate: Implications for stomatal fluxes of reduced stomatal sensitivity to soil drying in a typical grassland species. Glob. Chang. Biol. 2012, 18, 948-959. [CrossRef]

78. Hewitt, D.K.L.; Mills, G.; Hayes, F.; Wilkinson, S.; Davies, W. Highlighting the threat from current and near-future ozone pollution to clover in pasture. Environ. Pollut. 2014, 189, 111-117. [CrossRef]

79. Hewitt, D.K.L.; Mills, G.; Hayes, F.; Davies, W. The climate benefits of high-sugar grassland may be compromised by ozone pollution. Sci. Total Environ. 2016, 565, 95-104. [CrossRef] [PubMed]

80. Sharkey, T.D.; Bernacchi, C.J.; Farquhar, G.D.; Singsaas, E.L. Fitting photosynthetic carbon dioxide response curves for C3 leaves. Plantcell Environ. 2007, 30, 1035-1040.

81. De Kauwe, M.G.; Lin, Y.-S.; Wright, I.J. A test of the 'one-point method' for estimating maximum carboxylation capacity from field-measured, light-saturated photosynthesis. New Phytol. 2016, 210, 1130-1144. [CrossRef] [PubMed]

82. Bernacchi, C.; Singsaas, E.; Pimentel, C.; Portis, A., Jr.; Long, S. Improved temperature response functions for models of Rubisco-limited photosynthesis. Plantcell Environ. 2001, 24, 253-259. [CrossRef]

83. CLRTAP. Mapping Critical Levels for Vegetation. Chapter 3 of Manual on Methodologies and Criteria for Modelling and Mapping Critical Loads and Levels and Air Pollution Effects, Risks and Trends; UNECE: Geneva, Switzerland, 2017.

84. Klingberg, J.; Engardt, M.; Uddling, J.; Karlsson, P.E.; Pleijel, H. Ozone risk for vegetation in the future climate of Europe based on stomatal ozone uptake calculations. Tellus A 2011, 63, 174-187. [CrossRef]

85. R Core Team. A Language and Environment for Statistical Computing; R Foundation for Statistical Computing: Vienna, Austria, 2016.

86. Burnham, K.; Anderson, D. Model Selection and Multimodel Inference. A Practical Information-Theoretic Approach; Springer: New York, NY, USA, 2002.

87. Kuznetsova, A.; Brockhoff, P.B.; Christensen, R.H.B. lmerTest: Tests in Linear Mixed Effects Models. R package version 2.0-33. J. Stat. Softw. 2016, 82, 1-26. [CrossRef]

(C) 2019 by the authors. Licensee MDPI, Basel, Switzerland. This article is an open access article distributed under the terms and conditions of the Creative Commons Attribution (CC BY) license (http:/ / creativecommons.org/licenses/by/4.0/). 